1

5

\section{A panel of KSHV mutants in the polycistronic kaposin locus for precise analysis of} individual protein products

(1)

\footnotetext{
${ }^{1}$ Microbiology, Immunology and Infectious Diseases Department, University of Calgary,
} Mariel Kleer ${ }^{1,2,3}$, Grant MacNeil ${ }^{4}$, Eric S. Pringle ${ }^{4}$, and Jennifer A. Corcoran ${ }^{1,2,3,4 \#}$ Calgary, AB, Canada.

${ }^{2}$ Charbonneau Cancer Institute, University of Calgary, Calgary, AB, Canada. ${ }^{3}$ Snyder Institute for Chronic Diseases, University of Calgary, Calgary, AB, Canada. ${ }^{4}$ Department of Microbiology and Immunology, Dalhousie University, Halifax, NS, Canada ${ }^{*}$ Corresponding Author 


\section{$\underline{\text { Abstract }}$}

14 Kaposi's sarcoma-associated herpesvirus (KSHV) is the cause of several human cancers

15 including the endothelial cell (EC) malignancy, Kaposi's sarcoma. Unique KSHV genes absent from other human herpesvirus genomes, the "K-genes", are important for KSHV replication and

17 pathogenesis. Among these, the kaposin transcript is highly expressed in all phases of infection, but its complex polycistronic nature has hindered functional analysis to date. At least three proteins are produced from the kaposin transcript: Kaposin A (KapA), B (KapB), and C (KapC).

20 To determine the relative contributions of kaposin proteins during KSHV infection, we created a

21 collection of mutant viruses unable to produce kaposin proteins individually or in combination.

22 Kaposin-deficient latent iSLK cell lines displayed reduced viral genome copy number and often exhibited small LANA nuclear bodies; despite this, all were capable of progeny virion production. Primary infection with $\triangle \mathrm{KapB}$ virus revealed decreased LANA expression and viral genome copy number, yet providing KapB protein in trans failed to complement these defects, suggesting a requirement for the kaposin locus in cis. Our previous work showed that KapB was

27 sufficient to recapitulate the elevated proinflammatory cytokine transcripts associated with KS via the disassembly of RNA granules called processing bodies (PBs). We now show that KapB

29 is necessary for PB disassembly during latent KSHV infection. These findings demonstrate that our panel of kaposin-deficient viruses enables precise analysis of the respective contributions of

31 individual kaposin proteins to KSHV replication. Moreover, our mutagenesis approach serves as

32 a guide for the functional analysis of other complex multicistronic viral loci.

\section{$33 \underline{\text { Importance }}$}

34 Kaposi's sarcoma-associated herpesvirus (KSHV) expresses high levels of the kaposin transcript 35 during both latent and lytic phases of replication. Due to its repetitive, GC-rich nature and 
36 polycistronic coding capacity, until now no reagents existed to permit a methodical analysis of

37 the role of individual kaposin proteins in KSHV replication. We report the creation of a panel of

38 recombinant viruses and matched producer cell lines that delete kaposin proteins individually or

39 in combination. We demonstrate the utility of this panel by confirming the requirement of one

40 kaposin translation product to a key KSHV latency phenotype. This study describes a new panel

41 of molecular tools for the KSHV field to enable precise analysis of the roles of individual

42 kaposin proteins during KSHV infection. 


\section{Introduction}

Kaposi's sarcoma-associated herpesvirus (KSHV) is the infectious cause of the endothelial cell (EC) neoplasm, Kaposi's sarcoma (KS) and two rare lymphoproliferative

47 disorders: primary effusion lymphoma (PEL) and multicentric Castleman disease (MCD) (1-3).

48 Like all herpesviruses, KSHV establishes persistent, life-long infection of its human host, and displays two modes of infection, latent and lytic replication. Latency is the default replication program upon de novo infection in most cell types $(4,5)$. Following a transient period of lytic gene expression which serves to amplify genome copy number and evade the intrinsic immune response $(6,7)$, the viral episome is circularized and tethered to the host chromosome by the viral latency-associated nuclear antigen (LANA) (8). This results in formation of microscopically visible LANA-nuclear bodies (NB), which correlate with intracellular viral genome copy number (9-13). In the latent state, the viral genome is passively replicated and unevenly partitioned to daughter cells by host cell machinery $(10,14,15)$. The viral genome will remain in a highly chromatinized state until expression of the viral lytic switch protein, replication and transcription

58 activator (RTA), which is both necessary and sufficient for lytic reactivation (16-18). Following reactivation, lytic gene expression follows a prescribed temporal cascade with genome replication marking the transition from early to late gene expression $(19,20)$. More recent analyses using single cell approaches show that lytic reactivation is quite heterogenous in terms

62 of viral gene expression, host cell responses and outcomes (13, 21-23). The lytic replication phase produces progeny virions enabling transmission of the virus and culminates in cell death. (ECs) with an abnormal elongated or 'spindled' morphology. The majority of these tumor ECs 
67 hypothesized to play a role in KS, likely due to the ongoing production of progeny virions as well as the release of inflammatory and angiogenic factors $(14,28,29)$. Consistent with this, limiting viral lytic replication caused KS regression, suggesting that spontaneous lytic reactivation is required for ongoing infection of naïve cells in the tumor environment and

71 supports the cancer (30-32). latent gene expression to tumorigenesis has been explored extensively in both animal and cell culture models $(29,33-37)$. In vitro infection of primary ECs with KSHV recapitulates many of the features of KS tumors, including efficient establishment of viral latency. During latency, gene expression is limited to six consensus protein products produced from an approximately

77 10kbp region of the viral genome termed the latency locus (LANA, viral cyclin [v-Cyclin], and

78 viral fas-associated death domain (FADD)-like interleukin-1- $\beta$-converting enzyme (FLICE)

79 inhibitory protein [v-FLIP], Kaposins [Kap] A, B, and C) and 12 pre-miRNAs that are processed into at least 25 mature miRNAs (38-41) Using ectopic expression models, several latent gene

81 products have been shown to contribute to the establishment and maintenance of viral latency as

82 well as phenotypes associated with KS tumors (reviewed in $(42,43)$, but these studies have

83 predominantly focused on LANA, v-Cyclin and v-FLIP while the contributions of the

84 polycistronic kaposin locus is less clear. The kaposin mRNA was first identified as a marker of

85 KSHV latent infection in KS tumours in 1997 (27), and it remains the most abundant viral

87 coding capacity during latency and kaposin transcription is also upregulated during lytic

88 replication, suggesting that this region of the viral genome is important (45). Despite this, we 
89 still know very little about the role of the kaposin locus, or the proteins it encodes, during viral

90

91

92

93

94

95

96

97

98 replication.

The kaposin transcript is polycistronic and can be translated into at least three polypeptides, KapA, KapB and KapC (Figure 1A) (45), though we and others have observed multiple banding patterns on immunoblots that suggest additional translation products may also be derived from this locus $(45,46)$. Translation of KapA is initiated at a canonical AUG start codon located distal to the 5' end of the transcript and encodes a small membrane spanning protein (47-49). KapC is translated in the same reading frame as KapA, making its carboxyterminal region identical to KapA. However, translation of $\mathrm{KapC}$ is initiated at one of two noncanonical CUG start codons proximal to the 5' end of the transcript. Therefore, in addition to the KapA ORF, the KapC translation product contains two 23-amino acid direct repeat (DR) regions termed DR1 and DR2 (DR1: PSSPGTWCPPPREPGALLPGNLV and DR2:

APQEPGAAHPRNPARRTPGTRRG) which are derived from three sets of GC-rich 23nucleotide repeats (Figure 1A-B). Translation of KapB is initiated at one of two possible noncanonical CUG or GUG start codons that are most proximal to the 5' end of the kaposin mRNA, but uses an alternative reading frame to that of $\mathrm{KapA} / \mathrm{C}$. The resulting polypeptide is comprised largely of the same two 23-amino acid DRs (DR1 and DR2) found in KapC (Figure 1B) but lacks the C-terminal membrane spanning domain found in both KapA and KapC. Moreover, different isolates of KSHV display expansion or contraction of both direct repeats, the functional significance of which is unknown, yet regardless of the diversity in size, the core DR1 and DR2 repeats remain constant (45).

Our knowledge about individual kaposin protein function is derived largely from ectopic expression of individual kaposin proteins. KapA was reported to promote cell transformation in 
112

113

114

115

116

117

118

119

120

121

122

123

124

125

126

127

128

129

130

131

132

133

134

vitro and in vivo $(47,48)$; however, more recent work showed that this function stems from one of the viral miRNAs embedded within the KapA ORF (50). Previous work from our group has shown that KapB is sufficient to induce angiogenesis in an in vitro EC tubule formation assay and to promote actin stress fibers and elongation of ECs into a spindled morphology that recapitulates the morphology of latently infected KS tumor cells (51). KapB also is sufficient to induce the disassembly of RNA granules called processing bodies (PBs) $(51,52)$. PBs are important sites for the constitutive turnover or translational suppression of inflammatory cytokine mRNAs; PB loss correlates with enhanced levels of inflammatory cytokine transcripts that are normally targeted to PBs via an AU-rich destabilizing element (51, 53-57). However, our previous studies could not determine if KapB alone is necessary for these phenotypes during KSHV latent infection as we used RNA silencing to knockdown the kaposin transcript, a strategy that reduced expression of all kaposin proteins (51). No other studies have determined the role of individual kaposin translation products in KSHV latent or lytic replication cycles.

Here, we describe our use of the KSHV BAC16 bacterial artificial chromosome (BAC) and lambda Red recombination system (58) to construct a panel of viruses defective for specific kaposin locus products. We have constructed a triple deletion BAC16 $\mathrm{KapABC}$, a double deletion $\mathrm{BAC} 16 \Delta \mathrm{KapBC}$, and two single deletions $\mathrm{BAC} 16 \Delta \mathrm{KapB}$ and $\mathrm{BAC} 16 \Delta \mathrm{KapC}$ (Figure 1C). We confirmed that these viruses no longer express the deleted kaposin-derived proteins and show that all kaposin-deficient viruses are competent for genome replication and production of progeny virions. However, we show that $\Delta \mathrm{KapB}$ is significantly impaired, with markedly reduced genome copy number, small LANA nuclear bodies, and lower LANA expression. Moreover, these defects could not be complemented by providing KapB in trans. Additionally, $\triangle \mathrm{KapB}$ fails to cause $\mathrm{PB}$ disassembly following de novo infection of primary ECs, showing for 
135 the first time that KapB is necessary for PB disassembly during KSHV latency. With this panel

136 of kaposin recombinant KSHV viruses, it is now feasible to interrogate, with unprecedented

137 precision, the role of individual kaposin protein products in the context of KSHV latent or lytic

138 infection. 
Materials and Methods:

\section{Cell culture}

141 All cells were grown at $37^{\circ} \mathrm{C}$ with $5 \% \mathrm{CO}_{2}$ and atmospheric $\mathrm{O}_{2}$. HEK293T cells (ATCC) were

142 cultured in DMEM (Thermo Fisher) supplemented with $100 \mathrm{U} / \mathrm{mL}$ penicillin, $100 \mu \mathrm{g} / \mathrm{mL}$

143 streptomycin, $2 \mathrm{mM}$ L-glutamine (Thermo Fisher) and 10\% fetal bovine serum (FBS; Thermo

144 Fisher). iSLK.RTA cells (59) were cultured likewise with the addition of $1 \mu \mathrm{g} / \mathrm{mL}$ puromycin

145 and $250 \mu \mathrm{g} / \mathrm{mL}$ geneticin (Thermo Fisher). BAC16-iSLK.RTA cells were cultured similar to

146 iSLK.RTA cells, with the addition of $1200 \mu \mathrm{g} / \mathrm{mL}$ hygromycin B (Thermo Fisher). Human

147 umbilical vein endothelial cells (HUVECs, Lonza) were cultured in endothelial cell growth

148 medium (EGM-2) (Lonza). HUVECs were seeded onto gelatin $(0.1 \% \mathrm{w} / \mathrm{v}$ in PBS)-coated tissue

149 culture plates or glass coverslips.

\section{$\underline{\text { Lambda Red recombination for BAC16 mutagenesis }}$}

151 All mutagenesis was carried out in the BAC16 background (58) supplied in the GS1783 strain of

152 Escherichia coli (E.coli) (A generous gift from Dr. Jae Jung). All restriction enzymes were

153 purchased from New England Biolabs (NEB) and all primers were purchased from Invitrogen.

154 A kanamycin resistance and levansucrase enzyme cassette (KanSacB) was amplified using

155 primers (Table 1) with $40 \mathrm{bp}$ overhanging sequences that correspond to the $\mathrm{K} 12$ sequence of the

156 kaposin locus in the BAC16 genome. These primers also allowed for the introduction of BamHI

157 and NotI restriction endonuclease sites. The resulting PCR product was then subcloned into

158 pcDNA3.1+ (Addgene) using BamHI and NotI restriction endonucleases (pcDNA3.1+-

$159 \mathrm{KanSacB})$. 
To create single deletions of $\mathrm{KapB}$ and $\mathrm{KapC}$, two direct repeat (DR) region gene blocks were synthesized (BioBasic) where the third nucleotide of each codon of DR1 and DR2 was altered to insert premature stop codons and nonsynonymous mutations into one frame, while creating synonymous mutations in the other. This allowed the primary amino acid sequence of either $\mathrm{KapB}$ or KapC to be maintained while eliminating expression from the other ORF and vice versa. Primers were used to amplify the gene block with $40 \mathrm{bp}$ overhanging sequences that: 1) flank the gene block, 2) are homologous to the upstream and downstream regions of the DRs in the BAC16 genome, and 3) introduce NheI and BamHI restriction sites. The resulting PCR product was then subcloned into pcDNA3.1+-KanSacB (described above) using NheI and BamHI restriction sites (pcDNA3.1+-geneblock-KanSacB).

Lambda Red recombination was conducted in the GS1783 E.coli strain, which expresses the I-Sce enzyme and, in a temperature $\left(42^{\circ} \mathrm{C}\right)$ dependent manner, the lambda Red recombinase genes (beta, exo and gam). BAC16-GS1783 E. coli were cultured at $30^{\circ} \mathrm{C}$ in Lysogeny Broth (LB) containing $30 \mu \mathrm{g} / \mathrm{mL}$ chloramphenicol (Sigma-Aldrich) until reaching an optical density $\left(\mathrm{OD}_{600}\right)$ of $0.6-0.8$. Cultures were incubated for 30 minutes at $42^{\circ} \mathrm{C}$ prior to pelleting at room temperature at $3000 \times \mathrm{g}$ for 5 minutes. Bacterial pellets were resuspended in $\mathrm{ddH}_{2} \mathrm{O}$ and pelleted again at $3000 \mathrm{x} g$ for 5 minutes. This step was repeated once more, following which bacterial pellets were resuspended in $50 \mu \mathrm{L} \mathrm{ddH}_{2} 0$ and placed on ice. Meanwhile, pcDNA3.1+-geneblockKanSacB was digested with NheI and NotI restriction endonucleases to generate a linear DNA fragment for recombination. This was purified by $1 \%$ agarose gel electrophoresis and gel extracted according to QIAquick gel extraction kit (QIAGEN) standard protocol. The purified fragment was electroporated $\left(2.5 \mathrm{kV}, 25 \mu \mathrm{F}\right.$ BioRad Gene Pulser $\left.{ }^{\circledR} \mathrm{II}\right)$ into $50 \mu \mathrm{L}$ of dd $\mathrm{H}_{2} \mathrm{O}$-washed BAC16-GS1783 E.coli. Bacteria was recovered for 1 hour in $1 \mathrm{~mL}$ of LB media at $30^{\circ} \mathrm{C}$, plated 
onto LB agar plates containing $50 \mu \mathrm{g} / \mathrm{mL}$ kanamycin, and incubated at $30^{\circ} \mathrm{C}$ overnight $(\mathrm{O} / \mathrm{N})$.

Colonies were screened for successful recombination using colony PCR and two sets of screening primers designed to assess insert size and orientation (Table 1).

Colonies that produced bands of the expected size with both primer sets were inoculated into $1 \mathrm{ml}$ of LB containing $1 \%$ arabinose (Sigma-Aldrich) for 1 hour at $30^{\circ} \mathrm{C}$ to induce I-Sce expression to linearize the inserted $\mathrm{KanSacB}$ cassette. Bacteria were then incubated at $42^{\circ} \mathrm{C}$ for 30 minutes to induce recombinase gene expression and recovered for 1 hour at $30^{\circ} \mathrm{C}$ prior to plating on LB agar plates containing $30 \mu \mathrm{g} / \mathrm{mL}$ chloramphenicol and $5 \%$ sucrose, which selects for the loss of SacB that synthesizes a toxic compound in the presence of sucrose. Positive colonies were replica-plated on LB agar plates containing $50 \mu \mathrm{g} / \mathrm{mL}$ kanamycin. Those colonies that grew on both chloramphenicol and sucrose containing plates, and which were no longer kanamycin resistant, were screened by colony PCR for having undergone the second recombination to remove the KanSacB cassette and colony PCR products were verified by Sanger sequencing using primers as listed (Table 1).

\section{$\underline{\text { Isolation of BACmid DNA }}$}

BACmid DNA was isolated from GS1783 E.coli cultures of $5 \mathrm{~mL}$ of LB containing $30 \mu \mathrm{g} / \mathrm{mL}$ chloramphenicol grown $\mathrm{O} / \mathrm{N}$ at $30^{\circ} \mathrm{C}$. Bacteria was pelleted at $3000 \mathrm{x} g$ for 5 minutes, resuspended in buffer P1 containing RNaseA, lysed using alkaline lysis in buffer P2 and neutralized with buffer N3 (All reagents from QIAprep kits, QIAGEN). Following addition of buffer N3, lysates were placed on ice for 10 minutes prior to centrifugation at $17000 \times \mathrm{g}$ for 10 minutes to pellet precipitate. $750 \mu \mathrm{L}$ of supernatant was then mixed with $750 \mu \mathrm{L}$ of $100 \%$ isopropanol and placed on ice for 10 minutes prior to centrifugation at $17000 \mathrm{x} g$ for 10 minutes 
to pellet DNA. Supernatants were removed and the DNA pellet was left to air dry before being resuspended in $50 \mu \mathrm{L} 10 \mathrm{mM}$ Tris-Cl, $\mathrm{pH}$ 8.5. DNA was used immediately for transfection.

\section{Whole genome sequencing of KSHV BACs}

BACmid DNA was isolated from GS1783 E.coli cultures of $400 \mathrm{~mL}$ LB containing $30 \mu \mathrm{g} / \mathrm{mL}$ chloramphenicol grown $\mathrm{O} / \mathrm{N}$ at $30^{\circ} \mathrm{C}$. Bacteria was pelleted at $4000 \mathrm{x} g$ for 10 minutes at $4^{\circ} \mathrm{C}$. DNA was then extracted using the Qiagen Large Construct Kit in accordance with manufacturer's protocol. Critically, this isolation includes an exonuclease step which removes sheared E.coli DNA thereby allowing greater coverage of the BAC16 genome.

Whole genome sequencing was performed by the Centre for Health Genomics and Informatics (University of Calgary, Calgary, AB). Briefly, libraries were prepared using a NEB ultra II DNA Library Prep Kit for Illumina (NEB), quantified using a Kapa qPCR Library Kit (Roche), and sequenced using a MiSeq 500 v2 nano run (MiSeq Reagent Kit v2, Illumina) to generate 250+250bp paired end sequences. Raw reads were imported into Geneious Prime (60), paired and trimmed according to default settings. Reads were then aligned to the BAC16 reference genome (NCBI accession \#GQ994935). Average coverage was between $\sim 670$ and 1400x. Variations were identified based on a minimum coverage of 5 and minimum frequency in variation of 0.25 .

\section{$\underline{\text { Restriction length fragment polymorphism }}$}

Isolated BACmid DNA was digested overnight using NheI restriction enzyme (New England Biolabs) at $37^{\circ} \mathrm{C}$. Digested DNA fragments were then subjected to $1 \%$ agarose pulsed-field gel electrophoresis (PFGE) (Bio-Rad) using 0.5\% Tris/Borate/EDTA (TBE) buffer and the following conditions: $6 \mathrm{~V} / \mathrm{cm}, 120^{\circ}$ field angle, and switch time linearly ramped from $1 \mathrm{~s}$ to $5 \mathrm{~s}$ over $14-15$ 
$227 \mathrm{~h}$ (CHEF DR III, Bio-Rad). DNA bands were visualized by staining the gel with a solution of 0.5

$228 \mu \mathrm{g} / \mathrm{mL}$ ethidium bromide; excess stain was washed away with deionized water and the gel was

229 imaged on a ChemiDoc Touch Imaging System (Bio-Rad). DNA molecular weight standard

230 (BioRad, CHEF DNA size 8-48-kb) was used as reference.

231 Generation of Stable BAC16-iSLK.RTA cell lines

232 6-well plates of $70 \%$ confluent 293 T cells in antibiotic-free $10 \%$ FBS DMEM were washed once

233 with PBS, and media was replaced with $1 \mathrm{~mL}$ serum-free, antibiotic-free DMEM per well prior

234 to transfection. $5 \mathrm{uL}$ of re-suspended BAC16 DNA was incubated with $100 \mathrm{uL}$ Opti-MEM

235 reduced serum media (Thermo Fisher) for 5 minutes. Separately, 18 uL of polyethylenimine

236 (PEI, Polysciences) was incubated with $100 \mathrm{uL}$ Opti-MEM, also for 5 minutes. These two

237 mixtures were combined, incubated for 15 minutes, and added dropwise to each well. Cells were

238 incubated at $37^{\circ} \mathrm{C}$ for 4 hours at which time the media was replaced with antibiotic-free $10 \%$

239 FBS DMEM before further incubation at 37C. This transfection procedure was used to create

240 latent 293T stable cell lines shown in Figure 3.

At 48 hours post transfection, cells were expanded into 10-cm dishes. One day later,

242 media was removed and replaced with fresh antibiotic-free 10\% FBS DMEM containing 20

$243 \mathrm{ug} / \mathrm{mL}$ hygromycin (Thermo Fisher Scientific). The concentration of hygromycin was steadily

244 increased until a final concentration of $100 \mu \mathrm{g} / \mathrm{mL}$ was reached. When a confluent monolayer of

245 hygromycin-resistant BAC16 293T cells was achieved, cells were split once prior to liquid N2

246 storage in 90\% FBS and 10\% dimethyl sulfoxide (DMSO, Sigma-Aldrich).

To generate latent iSLK cells, each population of BAC16-transfected 293T cells was

248 individually co-cultured with puromycin-resistant iSLK.RTA cells in a 6-well dish at a 2:1 ratio. 
249 Once cells reached 80\% confluency, media was replaced with antibiotic-free 10\% FBS DMEM

250 containing $1 \mathrm{mM}$ sodium butyrate (NaB, Sigma-Aldrich) and $20 \mathrm{ng} / \mathrm{mL}$ 12-O-

251 tetradecanoylphorbol-13-acetate (TPA, Sigma-Aldrich) to induce latent BAC16-293T cells to

252 produce progeny virions. At 96 hours post reactivation, cells were expanded into $10 \mathrm{~cm}$ dishes.

253 One day following expansion, media was replaced with antibiotic-free $10 \%$ FBS DMEM

254 containing $10 \mathrm{ug} / \mathrm{mL}$ puromycin and $100 \mu \mathrm{g} / \mathrm{mL}$ hygromycin. Hygromycin concentration was

255 steadily increased in approximately $50 \mu \mathrm{g} / \mathrm{mL}$ increments until a final concentration of 240

$256 \mu \mathrm{g} / \mathrm{mL}$ was reached. Once a near-confluent monolayer of BAC16-iSLK.RTA cells was achieved,

257 cells were split once prior to liquid $\mathrm{N}_{2}$ storage as above. This procedure was used to create the

258 latent iSLK cell lines shown in Figure 3. A single latent iSLK cell line was created for

$259 \Delta \mathrm{Kap} \mathrm{ABC}, \triangle \mathrm{KapBC}$ and $\triangle \mathrm{KapC}$, while we derived four latent iSLK cell lines for $\triangle \mathrm{KapB}$

260 independently, as shown in Figure 6.

261 Production of KSHV BAC16 Wild-type and Recombinant Virus

262 Each population of BAC16-iSLK cells were reactivated using $1 \mathrm{ug} / \mathrm{mL}$ Doxycycline (Dox,

263 Sigma-Aldrich) and $1 \mathrm{mM} \mathrm{NaB}$ in antibiotic-free 10\% FBS DMEM. At 72 or 96 hours post

264 infection, supernatants were collected and clarified at $4000 \times \mathrm{g}$ to remove cellular debris and

265 virus-containing supernatant stored at $-80^{\circ} \mathrm{C}$ prior to use.

\section{De novo infection of Naïve HEK293T of HUVEC cells}

267 Sub-confluent (50-70\%) 12-well plates of 293T or HUVEC cells were incubated with viral

268 inoculum diluted in antibiotic and serum free DMEM containing $8 \mu \mathrm{g} / \mathrm{mL}$ hexadimethrine

269 bromide (polybrene; Sigma-Aldrich). Plates were centrifuged at $800 \times \mathrm{g}$ for 2 hours at room 
temperature (61), the inoculum was removed and replaced with either antibiotic-free $10 \%$ FBS

271

DMEM (293T) or full EGM-2 (HUVECs). Cells were then returned to the $37^{\circ} \mathrm{C}$ incubator.

272 Immunofluorescence

273 Cells were seeded onto 18mm round (\#1.5, Electron Microscopy Sciences) coverslips, infected

274 or treated as noted for each experiment and fixed for 10 minutes at room temperature in $4 \%(\mathrm{v} / \mathrm{v})$

275 paraformaldehyde (Electron Microscopy Sciences) in PBS. Samples were permeabilized with

$2760.1 \%(\mathrm{v} / \mathrm{v})$ Triton X-100 (Sigma-Aldrich) in PBS for $10 \mathrm{~min}$ at room temperature and blocked in

$2771 \%$ human AB serum (Sigma-Aldrich) for 1 hour at room temperature. Primary antibody was

278 diluted in 1\% human AB serum (Sigma-Aldrich) in PBS at the concentrations in Table 2 and

279 incubated overnight. The following day secondary antibody was likewise diluted in 1\% human

280 AB serum, alongside Hoechst (ThermoFisher Scientific) for nuclear staining, at the

281 concentrations in Table 2 and incubated for one hour. Samples were mounted with Prolong Gold

282 AntiFade mounting media (ThermoFisher Scientific). Images were captured using a Zeiss

283 AxioObserver Z1 microscope with the 40X objective unless otherwise stated.

$284 \quad$ Image analysis

285 Image analysis was performed using CellProfiler (cellprofiler.org), an open source software for 286 image analysis (62). Quantification of hedls/EDC4 and LANA-nuclear body (NB) puncta was 287 performed as previously described (63) with the following modifications. Rather than staining 288 cells with wheat germ agglutinin to identify cell periphery, individual cell cytoplasms were 289 defined based on a 150-pixel propagation away from the Hoescht-stained nucleus. The number 290 of Hedls/EDC4 puncta within a defined cell cytoplasm was reported. To quantify the number of 291 puncta in KSHV-infected cells, a gating strategy was applied to include only cells with LANA- 
292 positive nuclei and defined cell cytoplasms for Hedls/EDC4 puncta quantification. LANA-NBs

293 were defined by thresholding and size was measured using the "MeasureObjectSizeShape"

294 function, respectively. Object area refers to the number of pixels within the identified region. At

295 least 50 cells were quantified for each condition.

296 Immunoblotting

297 Cells were lysed in 1x Laemmli buffer (4\% SDS, 20\% glycerol, $120 \mathrm{mM}$ Tris-Cl (pH 6.8) and

$298 \mathrm{ddH}_{2} \mathrm{O}$ ) and stored at $-20^{\circ} \mathrm{C}$ until use. The DC Protein Assay (Bio-Rad) was used to quantify total

299 protein concentration as per the manufacturer's instructions. 10-15 $\mu \mathrm{g}$ of protein lysate was

300 resolved by SDS-PAGE on TGX Stain-Free acrylamide gels (BioRad). Membranes were blocked

301 in 5\% BSA or 5\% skim milk in Tris buffered saline-Tween20 (TBS-T). Primary and secondary

302 antibodies were diluted in $2.5 \%$ BSA or $2.5 \%$ skim milk, dilutions can be found in Table 1 .

303 Membranes were visualized using ProtoGlow ECL (National Diagnostics) and the ChemiDoc

304 Touch Imaging system (BioRad).

Intracellular viral genome qPCR

306 Confluent 6-well plates of BAC16-iSLK.RTA cells were lysed using a DNeasy Blood and Tissue

307 Kit (Qiagen) according to manufacturer's protocol. Isolated DNA was stored at $-20^{\circ} \mathrm{C}$ until

308 further use. DNA was diluted 1:30 prior to qPCR amplification using SsoFast EvaGreen

309 Supermix (Bio-Rad) and viral ORF26 or cellular $\beta$-actin (control) primers as listed in Table 3.

310 Fold change in viral genome copy number was determined using the $\Delta \Delta$-Quantitation cycle $(\mathrm{Cq})$

311 method.

312 DNase-protected viral genome qPCR 
313 Supernatants from reactivated iSLK cells were harvested and clarified at $4000 \mathrm{x} g$ for 5 minutes.

314 Aliquots of $180 \mu \mathrm{L}$ were stored separately at $-80^{\circ} \mathrm{C}$ prior to use. Supernatants were thawed at

$31537^{\circ} \mathrm{C}$ and mixed with $20 \mu \mathrm{L}$ of a $500 \mathrm{U}$ DNaseI (NEB), $10 \mathrm{X}$ buffer and nuclease free water

316 mixture and incubated at $37^{\circ} \mathrm{C}$ for 30 minutes. DNA was then extracted using a DNeasy Blood

317 and Tissue Kit with the following adjustments: per sample, $500 \mu \mathrm{g}$ of salmon sperm DNA

318 (Invitrogen) and $1 \mathrm{ng}$ of a luciferase (luc2) containing plasmid (pGL4.26, Clontech) was added

319 to buffer AL prior to lysis. DNA was not diluted prior to qPCR amplification using SsoFast

320 EvaGreen Supermix (Bio-Rad) and viral ORF26 and luc2 (control) primers as listed in Table 3.

321 Since every viral particle contains one genome, and one genome contains a single copy of the

322 ORF26 gene, the number of viral DNA molecules could be calculated. Fold change in viral

323 DNase-protected genomes was determined using the $\Delta \Delta$-Quantitation cycle $(\mathrm{Cq})$ method.

$324 \quad$ Lentivirus Production and Transduction

325 All lentiviruses were generated using a second-generation system. Briefly, HEK293T cells were

326 transfected with pSPAX2, MD2G, and the plasmid containing a gene of interest using

327 polyethylenimine (PEI, Polysciences). psPAX2 was a gift from Didier Trono (Addgene plasmid

$328 \quad \# 12260$ ) and pMD2.G was a gift from Didier Trono (Addgene plasmid \#12259). Viral

329 supernatants were harvested $48 \mathrm{~h}$ post-transfection, clarified using a $0.45 \mu \mathrm{m}$ polyethersulfone

330 filter (VWR), and frozen at $-80^{\circ} \mathrm{C}$ until use. For transduction, lentiviruses were thawed at $37^{\circ} \mathrm{C}$

331 and added to target cells in complete media containing $5 \mu \mathrm{g} / \mathrm{mL}$ polybrene (Sigma) for $24 \mathrm{~h}$. The

332 media was changed to selection media containing $5 \mu \mathrm{g} / \mathrm{mL}$ blasticidin (Thermo) and cells were

333 selected for at least $48 \mathrm{~h}$ before proceeding with experiments. 
12-well plates of $70 \%$ confluent 293 T cells in antibiotic-free $10 \%$ FBS DMEM were washed once with PBS, and media was replaced with $1 \mathrm{~mL}$ serum-free, antibiotic-free DMEM per well

337 prior to transfection. Cells transfected with $1 \mu \mathrm{g}$ of plasmids containing a gene of interest (Table 4) using polyethylenimine (PEI, Polysciences). 4 hours post transfection, media was replaced with antibiotic-free 10\% FBS DMEM.

\section{$\underline{\text { RT-qPCR }}$}

341 RNA was collected using a RNeasy Plus Mini Kit (Qiagen) according to the manufacturer's

342 instructions and stored at $-80^{\circ} \mathrm{C}$ until further use. RNA concentration was determined using a 343 NanoDrop One ${ }^{\mathrm{C}}$ (Thermo) and $500 \mathrm{ng}$ total was reverse transcribed using qScript XLT cDNA 344 SuperMix (QuantaBio) using a combination of random and oligo (dT) primers according to the 345 manufacturer's instructions. cDNA was diluted 1:10 for all RT-qPCR experiments and SsoFast 346 EvaGreen Mastermix (Biorad) was used to amplify cDNA. The $\Delta \Delta$ quantitation cycle $(\mathrm{Cq})$ 347 method was used to determine the fold change in expression of target transcripts. qPCR primer 348 sequences can be found in Table 3.

\section{Statistics}

Data shown are the mean \pm standard deviation (SD). Statistical significance was determined

351 using a paired Student's $t$-test. $P$ values are indicated in figures, $(*, \mathrm{P}<0.05 ; * *, \mathrm{P}<0.01 ; * * *$, $352 \mathrm{P}<0.001 ; * * * *, \mathrm{P}<0.0001$; ns, nonsignificant). All statistics were performed using GraphPad 353 Prism version 9.0.1.

Data Availability

355 All BAC16 virus sequences were deposited in the NCBI Sequence Read Archive (SRA) and are accessible through the following SRA accession numbers: SAMN19671530 (WT KSHV 
bioRxiv preprint doi: https://doi org/10.1101/2021 06 11.448153; this version posted September 7, 2021. The copyright holder for this preprint

(which was not certified by peer review) is the author/funder, who has granted bioRxiv a license to display the preprint in perpetuity. It is made available under aCC-BY-NC 4.0 International license.

357 BAC16), SAMN19671876 (KSHV BAC16 $\triangle$ KapABC), SAMN19671877 (KSHV BAC16

$358 \Delta$ KapBC), SAMN19671902 (KSHV BAC16 $\Delta$ KapB), and SAMN19672118 (KSHV BAC16

$359 \Delta \mathrm{KapC})$. 


\section{$\underline{\text { Results: }}$}

\section{Construction of a panel of kaposin recombinant BAC16 KSHV viruses}

Work on the kaposin locus has been limited by the lack of recombinant viruses that target

this region. To address this limitation, we created a panel of recombinant viruses that delete

KapA, KapB and KapC individually or in combination. These recombinant viruses were created

using the KSHV bacterial artificial chromosome clone BAC16, which contains the pBelo45

plasmid inserted between the vIRF-1 and ORF57 genes of the JSC-1 KSHV isolate $(58,63)$. This insertion encodes a red fluorescent protein (RFP) and a hygromycin resistance gene under the control of a constitutive cellular promoter, to enable visual and chemical selection of BAC16containing cells, respectively. The wildtype (WT) kaposin mRNA encodes three open reading longer made one or more of these protein products, we removed the DR regions that encompass the entire KapB ORF and most of the KapC ORF; in so doing, we created BAC16 $\mathrm{KapBC}$. We

373 then mutated the KapA start codon in the context of BAC $16 \Delta \mathrm{KapBC}$ to create

374 BAC16 1 KapABC. However, creating single deletions of KapB and KapC by simple start codon

375 mutagenesis proved to be extremely difficult due to the GC-rich and repetitive nature of this

376 region. We decided to use an amino acid recoding strategy to construct BAC16 genomes that

377 failed to code for either KapB or KapC, but not both. While both ORFs are comprised largely of

378 23-nucleotide DRs that translate into 23-amino acid DRs, the ORFs are in different reading

379 frames. Using the BAC16 genome (accession \#GQ994935), we designed two different gene

380 blocks with the nucleotide sequence of the DRs recoded. The first DNA construct was composed 381 of alternative codons that disrupted the protein coding capacity of the KapB ORF, due to several

382 nonsynonymous or nonsense mutations in the DRs, but contained only synonymous nucleotide 
changes in the KapC ORF that did not disrupt its amino acid sequence ( $\triangle \mathrm{KapB}$; Figure $1 \mathrm{~B})$. The second gene block coded for the inverse mutant; DRs were re-coded such that the KapC ORF contained nonsynonymous or nonsense mutations, while the KapB ORF contained synonymous mutations that did not disrupt its amino acid sequence ( $\triangle \mathrm{KapC}$; Figure $1 \mathrm{~B})$. This strategy also drastically decreased the GC-content of DR region from $78 \%$ to $59.6 \%$ or $63.3 \%$ for $\Delta \mathrm{KapB}$ and $\Delta \mathrm{KapC}$, respectively, facilitating the Lambda Red-based recombination events that followed and enabling us to use colony PCR screening during mutagenesis.

A two-step lambda Red-based recombination method in E.coli was used to facilitate BAC16 mutagenesis (Fig 1C) as in (64). We isolated each recombinant BACmid from E.coli and performed whole genome sequencing (WGS). Mapping of reads to the BAC16 reference genome (NCBI accession \#GQ994935) using Geneious Prime (60) revealed an average coverage per nucleotide of between 670 and 1430x. Subsequent analysis of variants revealed that no offtarget mutations had occurred during recombination (Figure 2A). Few variants were observed and these occurred within repetitive regions of the KSHV genome that also displayed low coverage, as previously shown (65-67). Outside of these, the only other variants detected were located in the region between the genes for vIRF-1 and ORF57 (Figure 2A). This is to be expected, as this is where the pBelo45 plasmid was inserted to facilitate the creation of BAC16, thereby altering the wild-type nucleotide sequence in this genomic location (58). We focused our attention to the kaposin DRs in WT BAC16. The repetitive nature of this sequence makes it difficult to resolve by WGS (68) and we observed low coverage. There was no coverage in the $\mathrm{DR}$ region for both $\triangle \mathrm{Kap} \mathrm{ABC}$ and $\triangle \mathrm{KapBC}$ constructs, consistent with the complete removal of the DRs (Figure 2A). In contrast, we observed high read coverage of the recoded kaposin regions in $\triangle \mathrm{KapB}$ and $\triangle \mathrm{KapC}$ viruses as recoding decreased the repetitive and GC-rich nature of the 
DRs (Figure 2B, only WT and $\Delta$ KapB shown for simplicity). The consensus sequences produced

407 for these regions matched our recoded gene blocks, reaffirming successful recombination. Given

408 the difficulty in resolving DR regions through Illumina sequencing (68), we also checked the

409 BAC16 genomes using restriction fragment length polymorphism. BAC16 DNA isolated from

410 E.coli was digested using the restriction enzyme NheI, followed by pulse field gel

411 electrophoresis (PFGE) to resolve fragments. We observed fragment sizes consistent with

412 predictions from in silico analysis using NCBI accession \#GQ994935 with the exception of the

413 fragment comprised largely of terminal repeats (TRs). We predicted that the TR-containing

414 fragment should migrate at $33 \mathrm{kbp}$; however, we did not observe a fragment of this size and

415 instead observed an unexpected fragment migrating at approximately $18 \mathrm{kbp}$. This suggested a

416 deletion of approximately $15 \mathrm{kbp}$, or 19 copies of the $801 \mathrm{bp}$ sequence, within this region. This

417 deletion has previously been observed in BAC16 (69) because the highly repetitive nature of the

418 TRs, as well as their high GC-content, renders them sensitive to recombination events $(70,71)$.

419 The smaller TR fragment was found in WT BAC16 and in all five recombinant viruses,

420 suggesting the event occurred prior to our mutagenesis, and that analysis of our panel kaposin-

421 deficient BAC16 viruses relative to WT would be unaffected. PFGE analysis also revealed a

422 second size discrepancy within the predicted kaposin-containing fragment which WGS was

423 unable to resolve due to the repetitive nature of the region. Based on in silico analysis, we

424 expected a $1200 \mathrm{bp}$ fragment, yet the digestion of our WT BAC16 genome produced a $1000 \mathrm{bp}$

425 fragment. This suggests that over time the WT BAC16 construct lost 200bp, or approximately

426 three 23-amino acid repeats, within the DR region, making our recoded kaposin locus in $\Delta \mathrm{KapB}$

427 and $\triangle \mathrm{KapC}$ viruses longer than the kaposin locus in WT BAC16. Because different KSHV

428 isolates possess variable numbers of repeats (45), it is not surprising to observe that this 
429 repetitive genomic area experienced DR contraction during BAC16 DNA copying, like has been

430 observed for the kaposin locus in KSHV. In future studies, we hope to decipher whether there is

431 any functional significance to the number of each kaposin DR1 and DR2 for KSHV replication.

\section{Generation of stable BAC16-iSLK.RTA cell lines}

After sequencing, the BAC16 mutant genomes were used to generate stable iSLK cell

434 lines. A workhorse cell line for KSHV research, iSLK cells have been engineered to express the

435 viral lytic switch protein, RTA, in a Doxycycline (Dox)-inducible manner (59). These cells are

especially useful for KSHV research as they maintain tight control of latency and produce large

437 quantities of virus following the addition of Dox (59). However, iSLK cells were refractory to

438 transfection in our hands; thus, we first transfected BAC16 DNA into 293T cells to create stable

439 BAC16-293Ts for each BACmid (Figure 3A), as in (69). The efficiency of 293T transfection

440 was between $20-30 \%$, as estimated by RFP expression. We gradually selected the transfected

441 cells with hygromycin until a confluent monolayer of RFP+ 293T cells was achieved (Figure

442 3B). Via quantitative PCR (qPCR) for viral DNA (ORF 26), we analyzed intracellular genome

443 copy number for each kaposin-deficient transfected 293T latent cell line and found that

444 intracellular genome copy number was similar to WT in each case (Figure 3C).

447 progeny virions to enable primary infection of iSLKs (72-75). All kaposin-deficient viruses were

448 able to infect naïve iSLKs judging by RFP expression. The population of kaposin-deficient latent

449 iSLK cells for each recombinant was then expanded via gradual selection in the presence of

450 hygromycin to eliminate uninfected cells and puromycin to eliminate BAC16-293T cells, until a

451 confluent layer of RFP-positive cells was achieved (Figure 3D). Immediately after selection, we 
analyzed the features of our iSLK latent cell lines. RFP-positive iSLKs cells were then stained by

453 immunofluorescence to visualize the viral latent protein LANA, which forms nuclear puncta

454 called LANA nuclear bodies (NBs) during KSHV infection (9-12) that were visible in all our

455 kaposin-deficient latent iSLK cell lines (Figure 3E), suggesting latency was successfully

456 established. We observed that not all LANA-positive cells were RFP-positive, a discrepancy that

457 has been reported by others (76). We also observed variable RFP intensity in our latent cell

458 populations and an overall decreased intensity of RFP signal in kaposin-deficient cell lines

459 relative to WT (Figure 3E). Using qPCR to quantify intracellular genome copy number of our

460 panel of latent iSLKs, we revealed that kaposin-deficient iSLKs contained $10-40 \%$ of the

461 genome copies observed in latent WT iSLKs (Figure 3F). These observations suggest the

462 possibility that KSHV recombinant viruses that lack the kaposin locus display defects in their

463 ability to establish latency and/or undergo genome amplification immediately following de novo

464 infection, a step that serves to increase latent episome copy number $(6,7)$.

Considering the possibility that kaposin-deficient KSHV recombinant viruses could be

466 less efficient at maintaining KSHV latency once already established, we decided to test how well

467 each latent cell population would maintain the viral genome compared to WT BAC16 latent

468 iSLKs in the absence of selective pressure. We passaged each latent cell line fifteen times in the

469 absence of hygromycin and determined intracellular genome copy number at each passage.

470 While WT BAC16 iSLKs displayed minimal episome loss over 15 passages $(14,77)$, we

471 observed that two of our kaposin-deficient recombinant viruses displayed accelerated genome

472 loss: $\triangle \mathrm{KapABC}$ and $\triangle \mathrm{KapBC}$, whereas $\Delta \mathrm{KapB}$ and $\Delta \mathrm{KapC}$ genome copy number remained

473 steady over time (Figure 4A-B). Taken together with Figure 3, these data suggest that the 
474 kaposin locus is important for the establishment of KSHV latency and may also contribute to its

475 maintenance.

476 Cells latently infected with kaposin-deficient viruses produce progeny virions when the predicted molecular weights of full-length $\mathrm{KapC}$ and $\mathrm{KapB}$, respectively. As expected, due to

493 chicken yolk IgY antibody (78) using a customized antibody production service and an epitope 494 predicted to be immunodominant; however, the antibody failed to detect KapA in WT infection or after ectopic expression and we did not use it further in these studies. 
To determine if each of our kaposin-deficient iSLK cell lines was capable of reactivation,

497 completion of a full lytic replication cycle, and the production of progeny virions, we reactivated

498 the cell lines with Dox, to activate RTA expression, and NaB and measured intracellular genome

499 copy number by qPCR at $24,48,72$, and 96 hours post reactivation. Genome copy number at

500 each time point was normalized to its matched starting genome copy number in latency since

501 each of the latent cell lines had a different episome copy number (Figure 3F) prior to

502 reactivation. For all recombinants, viral genome copy number significantly increased between 48

503 and 72 hours after reactivation (Figure 5B). WT and $\Delta \mathrm{KapB}$ viruses exhibited $\sim 15$-fold increase

504 in intracellular genome copy number over latent copy number, $\Delta \mathrm{KapABC}$ and $\Delta \mathrm{KapC}$ viruses

505 demonstrated a $\sim 40$-fold increase, and $\triangle \mathrm{KapBC}$ virus genome copy number increased $\sim 200$-fold

by 96 hours post reactivation. We then determined how the reactivation process altered viral

507 genome copy number for each kaposin-deficient recombinant relative to WT and observed that

508 all kaposin-deficient viruses except for $\Delta \mathrm{KapB}$ reached the same relative genome copy number

509 as WT by 96 hours post reactivation despite starting with less genomes than WT (Figure 5C).

510 These data show that all kaposin-deficient viruses are capable of genome replication to increase

511 viral DNA copy number after reactivation. Because the starting point of the reactivation process

512 was unequal (WT latent iSLK cells have more viral episomes at the 'starting point' of

513 reactivation than any of the kaposin-deficient iSLK cell lines, including $\triangle \mathrm{KapBC}$ latent iSLK

514 cells, Figure 3G), we were hesitant to draw quantitative conclusions about the efficiency of

515 genome replication after reactivation between our panel of kaposin-deficient viruses.

We next determined if kaposin-deficient reactivated iSLK cells released progeny virus

517 particles into the media. To do so, we harvested the virus-containing supernatant at 96 hours post

518 reactivation and subjected it to DNase digestion to eliminate unencapsidated viral DNA, then 
extracted the capsid-protected DNA and conducted qPCR for viral DNA (Figure 5D). We found that kaposin-deficient viruses released similar numbers of DNase-protected viral genomes to WT (Figure 5D). Although this observation suggests that the ability to package genomic material, assemble and release progeny virus does not require the kaposin locus, we and others have observed that extracellular genome copy number does not always correlate with infectious virus (21). To determine whether released virus from each kaposin-deficient latent iSLK cell line were competent to infect naïve cells, we incubated a naïve monolayer of 293 T cells with supernatant from reactivated iSLK cells and 24 hours later, stained cells for the latent protein LANA. We identified LANA-expressing cells in all $293 \mathrm{~T}$ cell monolayers infected by the panel of kaposindeficient recombinant viruses, (Figure 5E) showing that each kaposin-deficient virus can produce infectious progeny virions. This is consistent with our earlier observations using the 293T-iSLK co-culture system, as this method of latent cell line creation relies on successful lytic replication and virion production.

\section{Latent iSLK cells that lack Kaposin B display altered latency phenotypes}

Previous work from our lab used ectopic overexpression of KapB to characterize its function independent of viral infection. Consequently, we were most interested in analyzing the behaviour of the $\Delta \mathrm{KapB}$ recombinant virus. We reactivated WT and $\triangle \mathrm{KapB}-\mathrm{BAC} 16$ iSLKs to produce progeny virus, equalized extracellular genomic copy number, and infected naïve cells for 24 hours; however, we saw very few LANA-positive cells post infection (Figure 6A). Given the inconsistencies between stable BAC16 cell lines reported by others $(79,80)$, we decided to rederive another $\triangle \mathrm{KapB}$-latent iSLK cell line. Using the same population of $\triangle \mathrm{KapB}$-BAC16transfected 293Ts cells and an identical protocol for co-culture, selection, and expansion, we produced a new $\triangle \mathrm{KapB}$ iSLK cell line that we will refer to as $\triangle \mathrm{KapB}-2$ iSLKs, whereas our 
542 original $\Delta$ KapB iSLK cell line will be referred to as $\Delta$ KapB-1. Following $\Delta$ KapB-2 iSLK

543 reactivation, we noticed a greater cytopathic effect in reactivated $\Delta K a p B-2$ iSLKs than

544 previously observed in reactivated $\triangle$ KapB-1 iSLKs. We then equalized extracellular particle

545 number as above, infected naïve cells with $\triangle$ KapB-2 BAC16 and observed a 2-fold reduction in

546 LANA-positive cells compared to WT virus (Figure 6B), a great improvement compared to

$547 \Delta$ KapB-1. The large difference between infectious progeny production from $\Delta$ KapB-1 versus

$548 \Delta \mathrm{KapB}-2$ latent iSLKs prompted us to derive two additional $\triangle \mathrm{KapB}$ iSLK cell lines as described

549 above, termed $\Delta \mathrm{KapB}-3$ and $\Delta \mathrm{KapB}-4$. We compared several features between these four

$550 \Delta \mathrm{KapB}$ iSLK cell lines. We noted that although all four latent cell lines were RFP-positive,

$551 \Delta$ KapB-1 latent iSLK cells did not fluoresce as brightly as WT or the other $\triangle \mathrm{KapB}$ latent cell

552 lines (Figure 6C). We stained these latent cells for LANA nuclear bodies (NBs) and observed

553 several differences between LANA NBs present in latent WT iSLKs compared to the four

$554 \Delta \mathrm{KapB}$ latent iSLK cell lines (Figure 6D). Although WT latent cells had fewer LANA NBs per

555 cell than all four $\Delta \mathrm{KapB}$ latent cell lines (Figure 6E), WT LANA NBs averaged a much larger

556 area than in $\Delta \mathrm{KapB}$ latent cell lines (Figure $6 \mathrm{~F}$ ). Of the four $\Delta \mathrm{KapB}$ latent cell lines, $\Delta \mathrm{KapB}-4$

557 displayed LANA NB character that most closely resembled WT; namely, fewer LANA NBs that

558 were brighter and larger (Figure 6D-F). However, all four $\Delta$ KapB latent cell lines showed

559 episome copy number $\sim 10-25 \%$ that of WT latent iSLKs (Figure $6 \mathrm{G})$. Of these, $\Delta \mathrm{KapB}-2$ and

$560 \Delta$ KapB-4 had the higher genome copy number, consistent with $\Delta$ KapB-2 iSLK improved

561 reactivation $(\Delta \mathrm{KapB}-2$, Figure $6 \mathrm{~B})$ and $\Delta$ KapB-4 iSLK LANA NB character $(\Delta \mathrm{KapB}-4$, Figure

562 6D-F). In addition, all four $\Delta \mathrm{KapB}$ latent cell lines displayed reduced steady-state levels of

563 LANA protein compared to WT (Figure 6H). Taken together, these distinct differences clustered

564 the four $\triangle \mathrm{KapB}$ iSLK latent cell lines as defective compared to WT in terms of key latency 
phenotypes such as LANA NB area, steady-state levels of LANA protein, and KSHV genome copy number.

To determine if we could restore the defects associated with LANA expression in the established $\triangle \mathrm{KapB}$ iSLK cell lines, we used lentiviruses to ectopically express KapB or an empty vector control (Figure 7A-C). We used RT-qPCR to measure LANA transcript levels with and without complementation. $\triangle \mathrm{KapB}$ latent iSLK cell displayed $\sim 10-40 \%$ of the LANA RNA transcript levels detected in WT iSLKs (Figure 7A). Overexpression of KapB failed to alter LANA transcript levels compared to the control in any of the $\triangle \mathrm{KapB}$ iSLK cell lines (Figure 7B). Moreover, latent $\triangle \mathrm{KapB}$ iSLK cell lines showed reduced steady-state levels of LANA protein, as above, that was again not restored by providing KapB in trans (Figure 7C). To determine if complementation with KapB prior to primary infection and latency establishment could restore these defects, we transduced naïve iSLK cells with KapB-expressing or control lentiviruses prior to primary infection with $\Delta \mathrm{KapB}$. KapB expression did not complement the low genome copy number or reduced LANA protein level seen in $\triangle \mathrm{KapB}$-infected cells after primary infection (Figure 7D-F). To test if KapB could complement primary infection of another cell type, we transfected 293Ts with two different versions of KapB (KS lung and BAC16) prior to primary infection. Neither version of KapB was able to rescue low KSHV genome copy number or LANA protein levels after de novo infection of 293Ts (Figure 7G-I). Taken together, these data suggest that an aspect of the kaposin locus is required in cis, as providing the KapB polypeptide in trans, via non-targeted lentiviral integration, cannot complement the defects associated with $\Delta \mathrm{KapB}$ latency after primary infection.

\section{KapB is required for processing body disassembly after de novo infection of HUVECs}


We have previously shown that ectopic expression of KapB in human umbilical vein endothelial cells (HUVECs) is sufficient to recapitulate key phenotypes associated with KSHV

589 latency, including the disassembly of processing bodies (PBs), cytoplasmic RNA and protein 590 granules whose loss correlates with enhanced inflammatory cytokine RNAs (51, 53-57). To 591 determine if KapB was necessary for KSHV-induced PB loss, we reactivated $\triangle \mathrm{KapB}-2$ latent

592 iSLK cells and used this virus to infect HUVECs. After 96 hours post infection, we fixed the 593 infected cells and stained the monolayer for both LANA and for a PB-resident protein called 594 Hedls/EDC4 $(81,82)$. We observed that $\sim 80-90 \%$ of the cell monolayer was infected with either $\triangle \mathrm{KapB} \mathrm{BAC} 16$ or WT BAC16 virus. In LANA-positive cells that were infected with WT virus, we observed a two-fold decrease in PBs per infected cell compared to the mock-infected control

597 (Figure 8A-B), as shown previously (51). In LANA-positive cells infected with $\Delta$ KapB-2 virus, 598 PB numbers were not significantly altered relative to the mock-infected control (Figure 8A-B).

599 We also confirmed that WT-infected HUVECs expressed KapB, but that KapB was absent in 600 $\triangle \mathrm{KapB}$-infected HUVECs (Figure 8C). These data reveal for the first time that the KapB protein 601 is not only sufficient but also necessary for KSHV-induced PB disassembly following de novo 602 infection.

PBs constitutively repress or degrade cytokine transcripts that contain AU-rich elements

604 (AREs); accordingly, we and others have observed that PB disassembly correlates with enhanced 605 steady-state levels of some cytokine transcripts (51, 53-57). After primary infection of HUVECs with WT or $\triangle \mathrm{KapB}$, we measured steady-state levels of selected ARE-containing cytokine

607 transcripts by RT-qPCR (Figure 8D). We predicted that if PBs remain intact, as is after $\Delta$ KapB 608 infection, cytokine levels would be decreased relative WT-infected cells as the ARE-RNAs from 609 which they are expressed would be subject to PB-mediated decay. Consistent with this 
610 hypothesis, after infection with $\Delta \mathrm{KapB}$, IL-6 transcript levels were much reduced relative to that

611 observed with WT infection (Figure 8D). This is the expected response for a cytokine mRNA

612 that is shuttled to PBs for constitutive decay. However, we did not observe a strong difference

613 between steady-state levels of other ARE-containing cytokine transcripts (VEGF, IL-1 $\beta$, GM-

$614 \mathrm{CSF}$ ) after WT versus $\triangle \mathrm{KapB}$ infection (Figure 8D), as not all ARE-RNAs respond in the same

615 manner to altered PB dynamics, as shown in (83). Moreover, IL-6 mRNA levels are extremely

616 sensitive to changes in PBs (84) and we previously observed IL-6 transcript levels increase in

617 response PB disassembly induced by KapB (85). Taken together, these data show that KSHV-

618 induced PB disassembly correlates with 2-3-fold increased steady-state level of the IL-6

619 transcript and that both PB disassembly and enhanced IL-6 RNA levels are absent in cells

620 infected with $\Delta$ KapB.

We previously showed that ectopic expression of $\mathrm{KapB}$ is sufficient to induce primary

622 ECs to elongate and spindle, thereby recapitulating the morphology of infected cells within KS

623 lesions $(51,86)$. However, others have observed that ectopic expression of v-FLIP likewise

624 elicits EC spindling (87) and that the deletion of v-FLIP from the viral genome eliminates EC

625 spindling, although this effect is overcome at high multiplicity of infection (88). To test if KapB

626 is necessary for EC spindling, we used WT of $\triangle \mathrm{KapB} B \mathrm{BC} 16$, derived as above, to infect

627 HUVECs, fixed cells at 96hpi and visualized spindling at low magnification by brightfield

628 microscopy or at high magnification by staining fixed cells with phalloidin to label actin

629 filaments. Robust cell spindling was observed in LANA-positive, WT-infected cells (Figure 9).

630 We also observed spindled cells in LANA-positive, $\triangle$ KapB-infected HUVECs (Figure 9). We

631 conclude that although ectopic expression of KapB is sufficient to elicit EC spindling (51), it is

632 not necessary for EC spindling during KSHV latency. 


\section{Discussion:}

The kaposin locus comprises a significant portion of the coding capacity of the KSHV latency locus, yet its role in KSHV latent and lytic replication is not fully appreciated. Prior to

637 individual kaposin proteins in the context of KSHV infection. Here we described the construction and validation of a suite of kaposin-deficient recombinant viruses using the BAC16 bacterial artificial chromosome and a panel of corresponding stable iSLK cell lines. We deleted or recoded kaposin ORFs individually or in combination, generating several mutants: $\triangle \mathrm{Kap} A B C$, $\Delta \mathrm{KapBC}, \Delta \mathrm{KapB}$, and $\Delta \mathrm{KapC}$. We showed that all kaposin-deficient viruses established latency in iSLKs, replicated the viral genome upon reactivation, and produced progeny virions that could be used for de novo infection of naïve cells. Despite this, all kaposin-deficient latent iSLK cells

644 lines displayed reduced viral genome copy number during latency compared to WT. In addition, 645 we characterized four derivations of $\triangle \mathrm{KapB}$-iSLKs and showed that these cells not only had 646 markedly reduced genome copy number, but also reduced LANA NB area and LANA RNA and 647 protein levels. Attempts to complement the reduced expression of LANA in $\triangle \mathrm{KapB}$-iSLKs by ectopic expression of KapB had no effect, nor did attempts to complement the reduced KSHV

649 genome copy number after primary infection with $\Delta \mathrm{KapB}$ virus. Together, these data suggest that the kaposin locus plays a role in latency establishment that cannot be restored by

651 complementing with KapB protein in trans. Finally, we used $\Delta \mathrm{KapB} B A C 16$ to show that KapB

652 is not only sufficient but also necessary for KSHV-mediated PB disassembly following de novo

653 infection of primary ECs, verifying the contribution of an individual kaposin protein to KSHV

654 biology. This toolkit will allow us to understand the role of the kaposin locus in KSHV

655 replication with unprecedented precision, making it a significant advance for the field. 
657 the ectopic expression of individual kaposin ORFs $(47,51,52,89-91)$. To date, no

658 comprehensive kaposin-deficient BAC16 studies have been published. Toth et al., created a

659 kaposin knockout BAC16 virus by deleting a 1319-nucleotide region that included the coding region of KapA and the majority of the coding regions of $\mathrm{KapB}$ and $\mathrm{KapC}(92)$. This recombinant virus was used to test for the recruitment of proteins from polycomb repressive complexes 1 and 2 to two lytic viral promoters after primary infection of SLK cells (92). For this

663 phenotype, the kaposin knockout virus displayed no difference from WT, but aside from this, no 664 additional analyses related to this mutant were reported. Gallo et al. created a K12 mutant in which a kanamycin cassette disrupts the K12 ORF, but reported limited phenotypic analysis related to this virus (93). Finally, Campbell et al. investigated the role of the RTA-responsive

667 element (RRE) promoter in the kaposin locus, and in so doing created a K12 RRE-mutant;

668 however, this study focused solely on RTA-recruitment and genomic architecture (94). In the 669 current study, our recombinant viruses were created by removing all DR1 and DR2 sequences $670(\triangle \mathrm{KapBC})$ with or without mutagenesis of the KapA ORF start codon $(\triangle \mathrm{Kap} A B C)$, or by 671 replacing the DR region with alternatively coded nucleotide sequences $(\Delta \mathrm{KapB}$ and $\Delta \mathrm{KapC})$.

672 Our recoding strategy had several advantages. First, the translation potential of the kaposin locus 673 was reduced by insertion of multiple termination codons, eliminating expression of some protein 674 products while maintaining other ORFs by alternative codon usage. Second, recoding destroyed 675 the repetitive nature of the locus and decreased the GC-content, making the region much more 676 amenable to error-free homologous recombination. Third, in all of the recombinant kaposin677 mutant BACs, regulatory sequences for transcription and miRNA processing were left intact. We 678 also created corresponding latent iSLK cell lines for the kaposin-deficient BAC16 constructs. All 
679 four of these kaposin-deficient latent iSLK cell lines showed drastic reductions in viral genome

680

681

682

683

684

685

686

687

688

689

690

691

692

693

694

695

696

697

698

699

700

701 copy number compared to WT. The cell lines were created by co-culturing BAC16-transfected

HEK 293Ts with naïve iSLKs, a widely used method reported to be more efficient than direct

transfection of recombinant BAC16 DNA, that leverages cell-to-cell spread of virions from

reactivated $293 \mathrm{~T}$ cells to iSLKs $(5,59,69,95)$. Despite using this strategy, we failed to produce

latent cell lines that contained high genome copy numbers for any of the kaposin-deficient

BAC16 DNA. We repeated the co-culture procedure for the most impaired of these four times,

and each attempt yielded similar results; all four $\triangle \mathrm{KapB}$ iSLK cell lines displayed reduced viral

episome number and altered LANA NBs compared to WT BAC16 cells. Although these data are

consistent with the idea that kaposin-deficient viruses are impaired in one or more key steps

required for the establishment of latency, further study is required to characterize the nature of

this defect.

LANA expression and function is central to the establishment of KSHV latency. LANA forms homo-oligomers and binds the terminal repeat (TR) regions of the KSHV genome while simultaneously binding histones $\mathrm{H} 2 \mathrm{~A}$ and $\mathrm{H} 2 \mathrm{~B}$ of host chromatin, thereby tethering the viral DNA to host chromosomes $(8,10,11,96)$. This binding leads to the formation of structures called LANA NBs that colocalize with viral genomes $(10,97,98)$. The number of LANApositive puncta in an infected cell correlates with the number of viral episomes (13). KSHV de novo infection of a cell monolayer is heterogenous and results in variable levels of intracellular viral genomes between individual latent cells, and this heterogeneity is also represented by diverse LANA NB number per cell (13). Therefore, robust LANA NB staining is a marker for successful latency establishment. We and others have observed heterogenous LANA NB size within and between latent infected cells; however, the significance of this size variability is less 
clear. Because LANA can bind to nucleosomes in cellular chromosomes as well as those bound to viral episomes (15), LANA NBs are classified as supramolecular structures that cluster multiple viral episomes together $(12,98)$. Genome clustering was proposed to be an effective evolutionary strategy that allows KSHV to rapidly increase viral genome copy number per cell at the expense of total number of cells infected (15). It is not yet clear if a minimum number of viral episomes are required to create a supramolecular LANA NB after de novo infection; however, WT KSHV does preferentially form clustered LANA NBs (15). We have observed that latent $\triangle \mathrm{KapB}$ iSLK cells possess smaller and more uniform LANA NBs compared to those found in WT iSLK cells. Latent $\triangle \mathrm{KapB}$ iSLK cells express lower amounts of LANA RNA and protein, a phenotype that we could not complement by ectopic expression of KapB in trans.

Therefore, we report an additional correlative phenotype between low genome copy number, lower LANA expression and smaller LANA NBs observed in multiple derivations of $\Delta \mathrm{KapB}$ latent iSLK cell lines and speculate that $\triangle \mathrm{KapB}$ iSLK cells do not contain enough viral episomes and/or LANA protein to form large LANA NBs with clustered genomes.

The kaposin locus overlaps with one of two possible viral origins of lytic genome replication, called OriLytR. Though very few studies have investigated the contribution of OriLytR/kaposin to viral genome replication, detailed analyses on the function of OriLytL have revealed that it facilitates genome copying after viral reactivation and upon de novo infection (99-102). More recent work has shown an essential role for OriLytL transcription in viral genome replication after de novo infection (102). We speculate that loss of the GC-rich kaposin repeat region in our mutants impairs the contribution of OriLytR to viral genome copying that occurs after de novo infection, as was observed for a recombinant virus lacking OriLytL (102). A reduction in viral genome copy number after de novo infection would be predicted to impair 
725 latency establishment and diminish the clustering of viral episomes into larger LANA NBs,

726

727

728

729

730

731

732

733

734

735

736

737

738

739

740

741

742

743

744

745

746

747

which may explain the different LANA NB phenotype we observed in all four $\Delta \mathrm{KapB}$ iSLK

latent cell lines. Since we failed to complement the low genome copy number observed after

primary infection with $\Delta \mathrm{KapB}$, these data suggest that the role of the kaposin locus after primary

infection is derived from either the DNA locus or its RNA transcript in cis and not from the

polypeptide provided in trans. At odds with our model is that the loss of the kaposin region does

not appear to negatively impact viral genome replication after reactivation. We speculate that this

step is not as sensitive to the loss of one of two functional origins of lytic replication, as also

observed for loss of OriLytL (120). Further experimentation will be needed to reveal the precise

mechanism by which kaposin region may promote genome amplification after primary infection

and how this alters LANA NB formation, function, and latency establishment.

KSHV latency predominates in most cells in culture and in KS tumours, suggesting viral

proteins expressed at this time are important in promoting tumourigenesis. We have previously

shown that ectopic expression of KapB in primary ECs recapitulates two features of the KS

lesion: cell spindling and elevated inflammatory cytokine expression via PB disassembly. Using

the $\triangle \mathrm{KapB} \mathrm{BAC} 16$ recombinant virus, we analyzed if KapB was not only sufficient but

necessary for these KSHV-associated tumor phenotypes. We show that after de novo infection of

HUVECs, $\triangle \mathrm{KapB}$ BAC16 cells can induce cell spindling to a similar extent as WT BAC16

virus. These data are consistent with reports that the viral latent gene vFLIP is also capable of

causing endothelial cell spindling; therefore, the loss of KapB does not eliminate the spindling

phenotype (87). We propose that KapB and v-FLIP may act synergistically to promote EC

spindling during KSHV latency, and that in absence of one, the other is able to compensate. We

also used the $\triangle \mathrm{KapB} \mathrm{BAC} 16$ recombinant virus to determine if KapB was necessary for KSHV- 
induced PB disassembly. PBs are cytoplasmic sites for the constitutive turnover or translational suppression of ARE-containing inflammatory cytokine mRNAs (51, 53-57). We previously showed that latent KSHV infection of primary ECs caused PB disassembly (51). Here, we also observed that 96 hours after de novo infection of HUVECs with WT BAC16, PBs were disassembled. However, de novo infection of HUVECs with $\triangle \mathrm{KapB} B A C 16$ did not cause PB disassembly, and steady-state levels of IL-6 RNA, an ARE-containing cytokine transcript known to be regulated by PB levels, were reduced relative to that after WT infection (84). This reveals that KapB is both necessary and sufficient for PB disassembly during KSHV latency and represents the first time that a phenotypic function can be specifically attributed to a single kaposin protein in the context of KSHV infection.

Our group and others showed that PBs also decrease during lytic replication and that more than one viral protein is sufficient for this effect $(53,103)$. Here, we observed PB disassembly 96 hours after de novo infection of HUVECs, and we have previously shown PB disassembly in latent HUVECs (51). In contrast, Sharma et al. reported that PBs were not lost in a KSHV-infected latent primary effusion lymphoma cell line. This discrepancy could be attributed to the use of B-lymphocytes in their studies or their visualization of PBs by staining largely for the PB-resident protein GW182, an antigen that has been shown to adopt a punctate pattern distinct from other PB marker proteins $(103,104)$. Taken together, the observation that KSHV encodes multiple proteins in both phases of its replication to elicit PB disassembly suggests the functional relevance of this phenotype for viral infection. Because PBs constitutively repress many pro-inflammatory, angiogenic, or pro-tumourigenic cellular transcripts, we propose that the absence of microscopically visible PBs may contribute to the 
770 inflammatory and angiogenic KS microenvironment and that KapB is necessary for this effect in

771 KS lesions.

772 In summary, this work describes the construction and preliminary analysis of four

773 different kaposin-deficient BAC16 viruses and corresponding iSLK latent cell lines. We used

774 these mutants to specifically attribute the phenotype of PB disassembly following de novo

775 infection of primary to the viral protein KapB. This work also provides preliminary data to

776 suggest that the kaposin locus aids in the establishment of KSHV latency after primary infection,

777 a role that may suggest that the region derives function from its GC-rich direct repeats in

778 addition to its protein products. This is exciting because it suggests that the kaposin locus is truly

779 multipurpose, deriving distinct functions important for viral replication from its RNA transcript,

780 and its protein products. We hope these mutants will enable future studies to better evaluate the

781 roles of individual kaposin protein products during infection. Moreover, we believe our strategy

782 to recode protein products in multiple reading frames can serve as a mutagenesis roadmap for

783 understanding other complex, polycistronic viral loci. 


\section{Acknowledgements}

785 We sincerely thank the members of the Corcoran lab for helpful discussions about this work 786 including Ms. Julie Ryu for designing recoded $\Delta$ KapB sequence. We would like to thank Dr.

787 Craig McCormick (Dalhousie University) for valuable feedback on this manuscript and the 788 McCormick lab for plasmids, expertise and advice. We would like to thank Dr. Anne Vaahtokari 789 of the Charbonneau Microscopy Facility, UCalgary for microscopy support. We would like to 790 thank Dr. John Archibald (Dalhousie University) and the Archibald lab for help performing 791 pulse-field gel electrophoresis and Dr. Jae Jung (Cleveland Clinic) for sharing the BAC16-RFP

792 bacterial artificial chromosome. MK was supported by a CSM graduate training award, a CIHR

793 CGS-M scholarship, and a CIHR doctoral award. GM was supported by a CRTP graduate

794 training award. Operating funds to support this work derive from a CIHR Project Grant PJT-

795153210 to JAC.

796 Author Contributions

797 Mariel Kleer: Conceptualization, Experimentation, Analysis, Paper Writing

798 Grant MacNeil: Conceptualization, Experimentation, Analysis

799 Eric S. Pringle: Conceptualization, Supervision

800 Jennifer A. Corcoran: Conceptualization, Experimentation, Supervision, Funding Acquisition, 801 Project Administration, Paper Writing

\section{Conflict of Interest}

804 The authors have no competing interests to declare. 
805

806

807

808

809

810

811

812

813

814

815

816

817

818

819

820

821

822

823

824

825

\section{References}

1. Chang Y, Cesarman E, Pessin MS, Lee F, Culpepper J, Knowles DM, Moore PS. 1994. Identification of herpesvirus-like DNA sequences in AIDS-associated Kaposi's sarcoma. Science (80- ) https://doi.org/10.1126/science.7997879.

2. Cesarman E, Chang Y, Moore PS, Said JW, Knowles DM. 1995. Kaposi's sarcomaassociated herpesvirus-like DNA sequences in AIDS-related body-cavity—based lymphomas. N Engl J Med https://doi.org/10.1056/NEJM199505043321802.

3. Soulier J, Grollet L, Oksenhendler E, Cacoub P, Cazals-Hatem D, Babinet P, D'Agay MF, Clauvel JP, Raphael M, Degos L, Sigaux F. 1995. Kaposi’s sarcoma-associated herpesvirus-like DNA sequences in multicentric Castleman's disease. Blood https://doi.org/10.1182/blood.v86.4.1276.bloodjournal8641276.

4. Lagunoff M, Bechtel J, Venetsanakos E, Roy AM, Abbey N, Herndier B, Ganem D, McMahon M, Ganem D. 2002. De Novo Infection and Serial Transmission of Kaposi 's Sarcoma-Associated Herpesvirus in Cultured Endothelial Cells. J Virol https://doi.org/10.1128/JVI.76.5.2440.

5. Renne R, Blackbourn D, Whitby D, Levy J, Ganem D. 1998. Limited transmission of Kaposi's sarcoma-associated herpesvirus in cultured cells. J Virol https://doi.org/10.1128/JVI.72.6.5182-5188.1998.

6. Purushothaman P, Thakker S, Verma SC. 2015. Transcriptome Analysis of Kaposi's Sarcoma-Associated Herpesvirus during De Novo Primary Infection of Human B and Endothelial Cells . J Virol https://doi.org/10.1128/jvi.02507-14. 
$8267 . \quad$ Krishnan HH, Naranatt PP, Smith MS, Zeng L, Bloomer C, Chandran B. 2004.

827 Concurrent Expression of Latent and a Limited Number of Lytic Genes with Immune Modulation and Antiapoptotic Function by Kaposi's Sarcoma-Associated Herpesvirus Early during Infection of Primary Endothelial and Fibroblast Cells and Subsequent Decline of L. J Virol https://doi.org/10.1128/jvi.78.7.3601-3620.2004.

8. Cotter MA, Robertson ES. 1999. The latency-associated nuclear antigen tethers the Kaposi’s sarcoma- associated herpesvirus genome to host chromosomes in body cavity-

9. Szekely L, Kiss C, Mattsson K, Kashuba E, Pokrovskaja K, Juhasz A, Holmvall P, Klein G. 1999. Human herpesvirus-8-encoded LNA-1 accumulates in heterochromatinassociated nuclear bodies. J Gen Virol https://doi.org/10.1099/0022-1317-80-11-2889.

10. Ballestas ME, Chatis PA, Kaye KM. 1999. Efficient persistence of extrachromosomal KSHV DNA mediated by latency- associated nuclear antigen. Science (80- )

11. Schwam DR, Luciano RL, Mahajan SS, Wong L, Wilson AC. 2000. Carboxy Terminus of Human Herpesvirus 8 Latency-Associated Nuclear Antigen Mediates Dimerization, https://doi.org/10.1128/jvi.74.18.8532-8540.2000. 
848 13. Adang LA, Parsons CH, Kedes DH. 2006. Asynchronous Progression through the Lytic

849

850

851

852

853

854

855

856

857

858

859

860

861

862

863

864

865

866

867

868

869
Cascade and Variations in Intracellular Viral Loads Revealed by High-Throughput Single-

Cell Analysis of Kaposi’s Sarcoma-Associated Herpesvirus Infection. J Virol https://doi.org/10.1128/jvi.01156-06.

14. Grundhoff A, Ganem D. 2004. Inefficient establishment of KSHV latency suggests an additional role for continued lytic replication in Kaposi sarcoma pathogenesis. J Clin Invest https://doi.org/10.1172/JCI200417803.

15. Chiu YF, Sugden AU, Fox K, Hayes M, Sugden B. 2017. Kaposi's sarcoma-associated herpesvirus stably clusters its genomes across generations to maintain itself extrachromosomally. J Cell Biol https://doi.org/10.1083/jcb.201702013.

16. Lukac DM, Renne R, Kirshner JR, Ganem D. 1998. Reactivation of Kaposi's sarcomaassociated herpesvirus infection from latency by expression of the ORF 50 transactivator, a homolog of the EBV R protein. Virology https://doi.org/10.1006/viro.1998.9486.

17. Lukac DM, Kirshner JR, Ganem D. 1999. Transcriptional Activation by the Product of Open Reading Frame 50 of Kaposi's Sarcoma-Associated Herpesvirus Is Required for Lytic Viral Reactivation in B Cells. J Virol https://doi.org/10.1128/jvi.73.11.93489361.1999.

18. Xu Y, AuCoin DP, Huete AR, Cei SA, Hanson LJ, Pari GS. 2005. A Kaposi’s SarcomaAssociated Herpesvirus/Human Herpesvirus 8 ORF50 Deletion Mutant Is Defective for Reactivation of Latent Virus and DNA Replication. J Virol https://doi.org/10.1128/jvi.79.6.3479-3487.2005.

19. Sun R, Lin S-F, Staskus K, Gradoville L, Grogan E, Haase A, Miller G. 1999. Kinetics of 
Kaposi's Sarcoma-Associated Herpesvirus Gene Expression. J Virol https://doi.org/10.1128/jvi.73.3.2232-2242.1999.

20. Sun R, Lin SF, Gradoville L, Yuan Y, Zhu F, Miller G. 1998. A viral gene that activates lytic cycle expression of Kaposi’s sarcoma-associated herpesvirus. Proc Natl Acad Sci U S A https://doi.org/10.1073/pnas.95.18.10866.

21. Nakajima K, Guevara-Plunkett S, Chuang F, Wang K-H, Lyu Y, Kumar A, Luxardi G, Izumiya C, Soulika A, Campbell M, Izumiya Y. 2020. Rainbow Kaposi’s SarcomaAssociated Herpesvirus Revealed Heterogenic Replication with Dynamic Gene Expression. J Virol https://doi.org/10.1128/jvi.01565-19.

22. Chen CP, Lyu Y, Chuang F, Nakano K, Izumiya C, Jin D, Campbell M, Izumiya Y. 2017. Kaposi’s Sarcoma-Associated Herpesvirus Hijacks RNA Polymerase II To Create a Viral Transcriptional Factory. J Virol https://doi.org/10.1128/jvi.02491-16.

23. Okoid LM, Kimballid AK, Kasparid RE, Knoxid AN, Coleman CB, Rochford R, Chang T, Alderete B, van Dyk LF, Clambey ET. 2019. Multidimensional analysis of gammaherpesvirus RNA expression reveals unexpected heterogeneity of gene expression. PLoS Pathog https://doi.org/10.1371/journal.ppat.1007849.

24. Zhong W, Wang H, Herndier B, Ganem D. 1996. Restricted expression of Kaposi sarcoma-associated herpesvirus (human herpesvirus 8) genes in Kaposi sarcoma. Proc Natl Acad Sci U S A https://doi.org/10.1073/pnas.93.13.6641.

25. Katano H, Sato Y, Kurata T, Mori S, Sata T. 2000. Expression and localization of human herpesvirus 8-encoded proteins in primary effusion lymphoma, Kaposi's sarcoma, and multicentric Castleman's disease. Virology https://doi.org/10.1006/viro.2000.0196. 
26. Katano H, Sato Y, Itoh H, Sata T. 2001. Expression of human herpesvirus 8 (HHV-8)encoded immediate early protein, open reading frame 50, in HHV-8-associated diseases. $\mathrm{J}$ Hum Virol.

27. Staskus KA, Gebhard K, Haase AT, Zhong W, Wang H, Renne R, Ganem D, Herndier B, Beneke J, Pudney J, Anderson DJ. 1997. Kaposi’s sarcoma-associated herpesvirus gene expression in endothelial (spindle) tumor cells. J Virol.

28. Bais C, Santomasso B, Coso O, Arvanitakis L, Raaka EG, Gutkind JS, Asch AS, Cesarman E, Gerhengorn MC, Mesri EA. 1998. G-protein-coupled receptor of Kaposi's sarcoma-associated herpesvirus is a viral oncogene and angiogenesis activator. Nature https://doi.org/10.1038/34193.

29. Montaner S, Sodhi A, Molinolo A, Bugge TH, Sawai ET, He Y, Li Y, Ray PE, Gutkind JS. 2003. Endothelial infection with KSHV genes in vivo reveals that vGPCR initiates Kaposi's sarcomagenesis and can promote the tumorigenic potential of viral latent genes. Cancer Cell https://doi.org/10.1016/S1535-6108(02)00237-4.

30. Mazzi R, Parisi SG, Sarmati L, Uccella I, Nicastri E, Carolo G, Gatti F, Concia E, Andreoni M. 2001. Efficacy of cidofovir on human herpesvirus 8 viraemia and Kaposi's sarcoma progression in two patients with AIDS [1]. AIDS.

31. Mesri EA, Feitelson MA, Munger K. 2014. Human viral oncogenesis: A cancer hallmarks analysis. Cell Host Microbe.

32. Martin DF, Kuppermann BD, Wolitz RA, Palestine AG, Li H, Robinson CA. 1999. Oral Ganciclovir for Patients with Cytomegalovirus Retinitis Treated with a Ganciclovir Implant. N Eng1 J Med https://doi.org/10.1056/nejm199904083401402. 
914 33. Bravo Cruz AG, Damania B. 2019. In Vivo Models of Oncoproteins Encoded by Kaposi’s Sarcoma-Associated Herpesvirus . J Virol https://doi.org/10.1128/jvi.01053-18.

34. Friborg J, Kong WP, Hottlger MO, Nabel GJ. 1999. p53 Inhibition by the LANA protein of KSHV protects against cell death. Nature https://doi.org/10.1038/47266.

35. Fujimuro M, Wu FY, Aprhys C, Kajumbula H, Young DB, Hayward GS, Hayward SD. 2003. A novel viral mechanism for dysregulation of $\beta$-catenin in Kaposi's sarcomaassociated herpesvirus latency. Nat Med https://doi.org/10.1038/nm829.

36. Radkov SA, Kellam P, Boshoff C. 2000. The latent nuclear antigen of Kaposi sarcomaassociated herpesvirus targets the retinoblastoma-E2F pathway and with the oncogene Hras transforms primary rat cells. Nat Med https://doi.org/10.1038/80459.

37. Sin SH, Dittmer DP. 2013. Viral latency locus augments B-cell response in vivo to induce chronic marginal zone enlargement, plasma cell hyperplasia, and lymphoma. Blood https://doi.org/10.1182/blood-2012-03-415620.

38. Qin J, Li W, Gao SJ, Lu C. 2017. KSHV microRNAs: Tricks of the Devil. Trends Microbiol.

39. Arias C, Weisburd B, Stern-Ginossar N, Mercier A, Madrid AS, Bellare P, Holdorf M, https://doi.org/10.1371/journal.ppat.1003847. 
Kaposi’s Sarcoma-Associated Herpesvirus (Human Herpesvirus 8) Genome in a Body Cavity-Based Lymphoma Cell Line (BC-1). J Virol https://doi.org/10.1128/jvi.72.2.1005-

41. Dittmer D, Lagunoff M, Renne R, Staskus K, Haase A, Ganem D. 1998. A Cluster of Latently Expressed Genes in Kaposi’s Sarcoma-Associated Herpesvirus. J Virol https://doi.org/10.1128/jvi.72.10.8309-8315.1998.

42. Schulz TF, Cesarman E. 2015. Kaposi Sarcoma-associated Herpesvirus: Mechanisms of oncogenesis. Curr Opin Virol.

43. Dittmer DP, Damania B. 2016. Kaposi sarcoma-associated herpesvirus: Immunobiology, oncogenesis, and therapy. J Clin Invest.

44. Rose TM, Bruce AG, Barcy S, Fitzgibbon M, Matsumoto LR, Ikoma M, Casper C, Orem J, Phipps W. 2018. Quantitative RNAseq analysis of Ugandan KS tumors reveals KSHV gene expression dominated by transcription from the LTd downstream latency promoter. PLoS Pathog https://doi.org/10.1371/journal.ppat.1007441.

45. Sadler R, Wu L, Forghani B, Renne R, Zhong W, Herndier B, Ganem D. 1999. A complex translational program generates multiple novel proteins from the latently expressed kaposin (K12) locus of Kaposi’s sarcoma-associated herpesvirus. J Virol.

46. McCormick C, Ganem D. 2006. Phosphorylation and Function of the Kaposin B Direct Repeats of Kaposi's Sarcoma-Associated Herpesvirus. J Virol https://doi.org/10.1128/jvi.02331-05.

47. Kliche S, Nagel W, Kremmer E, Atzler C, Ege A, Knorr T, Koszinowski U, Kolanus W, 
Haas J. 2001. Signaling by human herpesvirus 8 kaposin a through direct membrane recruitment of cytohesin-1. Mol Cell https://doi.org/10.1016/S1097-2765(01)00227-1.

48. Muralidhar S, Pumfery AM, Hassani M, Sadaie MR, Kishishita M, Brady JN, Doniger J, Medveczky P, Rosenthal LJ. 1998. Identification of kaposin (open reading frame K12) as a human herpesvirus 8 (Kaposi’s sarcoma-associated herpesvirus) transforming gene. J Virol.

49. Tomkowicz B, Singh SP, Cartas M, Srinivasan A. 2002. Human herpesvirus-8 encoded kaposin: Subcellular localization using immunofluorescence and biochemical approaches. DNA Cell Biol https://doi.org/10.1089/10445490252925413.

50. Forte E, Raja AN, Shamulailatpam P, Manzano M, Schipma MJ, Casey JL, Gottwein E. 2015. MicroRNA-Mediated Transformation by the Kaposi’s Sarcoma-Associated Herpesvirus Kaposin Locus. J Virol https://doi.org/10.1128/jvi.03317-14.

51. Corcoran JA, Johnston BP, McCormick C. 2015. Viral Activation of MK2-hsp27p115RhoGEF-RhoA Signaling Axis Causes Cytoskeletal Rearrangements, P-body Disruption and ARE-mRNA Stabilization. PLoS Pathog https://doi.org/10.1371/journal.ppat.1004597.

52. McCormick C, Ganem D. 2005. The kaposin B protein of KSHV activates the p38/MK2 pathway and stabilizes cytokine mRNAs. Science (80- ) https://doi.org/10.1126/science.1105779.

53. Corcoran JA, Khaperskyy DA, Johnston BP, King CA, Cyr DP, Olsthoorn A V., McCormick C. 2012. Kaposi’s Sarcoma-Associated Herpesvirus G-Protein-Coupled Receptor Prevents AU-Rich-Element-Mediated mRNA Decay. J Virol 
https://doi.org/10.1128/jvi.00597-12.

979

980

981

982

983

984

985

986

987

988

989

990

991

992

993

994

995

996

997

998

999

54. Blanco FF, Sanduja S, Deane NG, Blackshear PJ, Dixon DA. 2014. Transforming Growth

Factor Regulates P-Body Formation through Induction of the mRNA Decay Factor

Tristetraprolin. Mol Cell Biol https://doi.org/10.1128/mcb.01020-13.

55. Franks TM, Lykke-Andersen J. 2007. TTP and BRF proteins nucleate processing body formation to silence mRNAs with AU-rich elements. Genes Dev

https://doi.org/10.1101/gad.1494707.

56. Vindry C, Marnef A, Broomhead H, Twyffels L, Ozgur S, Stoecklin G, Llorian M, Smith CW, Mata J, Weil D, Standart N. 2017. Dual RNA Processing Roles of Pat1b via Cytoplasmic Lsm1-7 and Nuclear Lsm2-8 Complexes. Cell Rep https://doi.org/10.1016/j.celrep.2017.06.091.

57. Hubstenberger A, Courel M, Bénard M, Souquere S, Ernoult-Lange M, Chouaib R, Yi Z, Morlot JB, Munier A, Fradet M, Daunesse M, Bertrand E, Pierron G, Mozziconacci J, Kress M, Weil D. 2017. P-Body Purification Reveals the Condensation of Repressed mRNA Regulons. Mol Cell https://doi.org/10.1016/j.molcel.2017.09.003.

58. Brulois KF, Chang H, Lee AS-Y, Ensser A, Wong L-Y, Toth Z, Lee SH, Lee H-R, Myoung J, Ganem D, Oh T-K, Kim JF, Gao S-J, Jung JU. 2012. Construction and Manipulation of a New Kaposi’s Sarcoma-Associated Herpesvirus Bacterial Artificial Chromosome Clone. J Virol https://doi.org/10.1128/jvi.01019-12.

59. Myoung J, Ganem D. 2011. Generation of a doxycycline-inducible KSHV producer cell line of endothelial origin: Maintenance of tight latency with efficient reactivation upon induction. J Virol Methods https://doi.org/10.1016/j.jviromet.2011.03.012. 
1000

1001

1002

1003

1004

1005

1006

1007

1008

1009

1010

1011

1012

1013

1014

1015

1016

1017

1018

1019

1020

1021

60. Kearse M, Moir R, Wilson A, Stones-Havas S, Cheung M, Sturrock S, Buxton S, Cooper

A, Markowitz S, Duran C, Thierer T, Ashton B, Meintjes P, Drummond A. 2012.

Geneious Basic: An integrated and extendable desktop software platform for the

organization and analysis of sequence data. Bioinformatics

https://doi.org/10.1093/bioinformatics/bts199.

61. Yoo SM, Ahn AK, Seo T, Hong HB, Chung MA, Jung SD, Cho H, Lee MS. 2008.

Centrifugal enhancement of Kaposi's sarcoma-associated virus infection of human

endothelial cells in vitro. J Virol Methods https://doi.org/10.1016/j.jviromet.2008.07.026.

62. Carpenter AE, Jones TR, Lamprecht MR, Clarke C, Kang IH, Friman O, Guertin DA, Chang JH, Lindquist RA, Moffat J, Golland P, Sabatini DM. 2006. CellProfiler: Image analysis software for identifying and quantifying cell phenotypes. Genome Biol https://doi.org/10.1186/gb-2006-7-10-r100.

63. Cannon JS, Ciufo D, Hawkins AL, Griffin CA, Borowitz MJ, Hayward GS, Ambinder RF. 2000. A New Primary Effusion Lymphoma-Derived Cell Line Yields a Highly Infectious Kaposi’s Sarcoma Herpesvirus-Containing Supernatant. J Virol https://doi.org/10.1128/jvi.74.21.10187-10193.2000.

64. Tischer BK, Von Einem J, Kaufer B, Osterrieder N. 2006. Two-step Red-mediated recombination for versatile high-efficiency markerless DNA manipulation in Escherichia coli. Biotechniques https://doi.org/10.2144/000112096.

65. Santiago JC, Goldman JD, Zhao H, Pankow AP, Okuku F, Schmitt MW, Chen LH, Hill CA, Casper C, Phipps WT, Mullins JI. 2021. Intra-host changes in Kaposi sarcomaassociated herpesvirus genomes in Ugandan adults with Kaposi sarcoma. PLoS Pathog 
https://doi.org/10.1371/journal.ppat.1008594.

1023

1024

1025

1026

1027

1028

1029

1030

1031

1032

1033

1034

1035

1036

1037

1038

1039

1040

1041

1042

1043

66. BeltCappellino A, Majerciak V, Lobanov A, Lack J, Cam M, Zheng Z-M. 2019.

CRISPR/Cas9-Mediated Knockout and In Situ Inversion of the ORF57 Gene from All Copies of the Kaposi's Sarcoma-Associated Herpesvirus Genome in BCBL-1 Cells . J Virol https://doi.org/10.1128/jvi.00628-19.

67. Sallah N, Palser AL, Watson SJ, Labo N, Asiki G, Marshall V, Newton R, Whitby D, Kellam P, Barroso I. 2018. Genome-wide sequence analysis of Kaposi sarcoma-associated herpesvirus shows diversification driven by recombination. J Infect Dis https://doi.org/10.1093/infdis/jiy427.

68. Tørresen OK, Star B, Mier P, Andrade-Navarro MA, Bateman A, Jarnot P, Gruca A, Grynberg M, Kajava A V., Promponas VJ, Anisimova M, Jakobsen KS, Linke D. 2019. Tandem repeats lead to sequence assembly errors and impose multi-level challenges for genome and protein databases. Nucleic Acids Res.

69. Jain V, Plaisance-Bonstaff K, Sangani R, Lanier C, Dolce A, Hu J, Brulois K, Haecker I, Turner P, Renne R, Krueger B. 2016. A toolbox for Herpesvirus miRNA research: Construction of a complete set of KSHV miRNA Deletion Mutants. Viruses https://doi.org/10.3390/V8020054.

70. Russo JJ, Bohenzky RA, Chien MC, Chen J, Yan M, Maddalena D, Parry JP, Peruzzi D, Edelman IS, Chang Y, Moore PS. 1996. Nucleotide sequence of the Kaposi sarcomaassociated herpesvirus (HHV8)Proceedings of the National Academy of Sciences of the United States of America.

71. Dheekollu J, Chen H-S, Kaye KM, Lieberman PM. 2013. Timeless-Dependent DNA 
Replication-Coupled Recombination Promotes Kaposi’s Sarcoma-Associated Herpesvirus Episome Maintenance and Terminal Repeat Stability. J Virol https://doi.org/10.1128/jvi.02211-12.

72. Deutsch E, Cohen A, Kazimirsky G, Dovrat S, Rubinfeld H, Brodie C, Sarid R. 2004. Role of Protein Kinase C $\delta$ in Reactivation of Kaposi's Sarcoma-Associated Herpesvirus. J Virol https://doi.org/10.1128/jvi.78.18.10187-10192.2004.

73. Miller G, Rigsby MO, Heston L, Grogan E, Sun R, Metroka C, Levy JA, Gao S-J, Chang Y, Moore P. 1996. Antibodies to Butyrate-Inducible Antigens of Kaposi’s SarcomaAssociated Herpesvirus in Patients with HIV-1 Infection. N Engl J Med https://doi.org/10.1056/nejm199605163342003.

74. Chen J, Ueda K, Sakakibara S, Okuno T, Parravicini C, Corbellino M, Yamanishi K. 2001. Activation of latent Kaposi's sarcoma-associated herpesvirus by demethylation of the promoter of the lytic transactivator. Proc Natl Acad Sci U S A https://doi.org/10.1073/pnas.051004198.

75. Renne R, Zhong W, Herndier B, McGrath M, Abbey N, Kedes D, Ganem D. 1996. Lytic growth of Kaposi's sarcoma-associated herpesvirus (human herpesvirus 8) in culture. Nat Med https://doi.org/10.1038/nm0396-342.

76. Ellison TJ, Kedes DH. 2014. Variable episomal silencing of a recombinant herpesvirus renders its encoded GFP an unreliable marker of infection in primary cells. PLoS One https://doi.org/10.1371/journal.pone.0111502.

77. Haddad CO, Kalt I, Shovman Y, Xia L, Schlesinger Y, Sarid R, Parnas O. 2021. Targeting the Kaposi's sarcoma-associated herpesvirus genome with the CRISPR-Cas9 platform in 
latently infected cells. Virol J https://doi.org/10.1186/s12985-021-01527-x.

1067

1068

1069

1070

1071

1072

1073

1074

1075

1076

1077

1078

1079

1080

1081

1082

1083

1084

1085

1086

78. Wen J, Zhao S, He D, Yang Y, Li Y, Zhu S. 2012. Preparation and characterization of egg yolk immunoglobulin Y specific to influenza B virus. Antiviral Res https://doi.org/10.1016/j.antiviral.2011.11.005.

79. Brulois K, Toth Z, Wong L-Y, Feng P, Gao S-J, Ensser A, Jung JU. 2014. Kaposi’s Sarcoma-Associated Herpesvirus K3 and K5 Ubiquitin E3 Ligases Have Stage-Specific Immune Evasion Roles during Lytic Replication. J Virol https://doi.org/10.1128/jvi.00873-14.

80. Butnaru M, Gaglia MM. 2019. The kaposi's sarcoma-associated herpesvirus protein orf42 is required for efficient virion production and expression of viral proteins. Viruses https://doi.org/10.3390/v11080711.

81. Jiang HY, Yang WH, Gulick T, Bloch KD, Bloch DB. 2005. Ge-1 is a central component of the mammalian cytoplasmic mRNA processing body. RNA https://doi.org/10.1261/rna.2142405.

82. Standart N, Weil D. 2018. P-Bodies: Cytosolic Droplets for Coordinated mRNA Storage. Trends Genet.

83. Tenekeci U, Poppe M, Beuerlein K, Buro C, Müller H, Weiser H, Kettner-Buhrow D, Porada K, Newel D, Xu M, Chen ZJ, Busch J, Schmitz ML, Kracht M. 2016. K63Ubiquitylation and TRAF6 Pathways Regulate Mammalian P-Body Formation and mRNA Decapping. Mol Cell https://doi.org/10.1016/j.molcel.2016.05.017.

84. Seto E, Yoshida-Sugitani R, Kobayashi T, Toyama-Sorimachi N. 2015. The assembly of 
EDC4 and Dcpla into processing bodies is critical for the translational regulation of IL-6.

PLoS One https://doi.org/10.1371/journal.pone.0123223.

85. Robinson C-A, Singh GK, Castle EL, Boudreau BQ, Corcoran JA. 2021. The

NDP52/CALCOCO2 selective autophagy receptor controls processing body disassembly. bioRxiv.

86. Ciufo DM, Cannon JS, Poole LJ, Wu FY, Murray P, Ambinder RF, Hayward GS. 2001. Spindle Cell Conversion by Kaposi's Sarcoma-Associated Herpesvirus: Formation of Colonies and Plaques with Mixed Lytic and Latent Gene Expression in Infected Primary Dermal Microvascular Endothelial Cell Cultures. J Virol https://doi.org/10.1128/jvi.75.12.5614-5626.2001.

87. Grossmann C, Podgrabinska S, Skobe M, Ganem D. 2006. Activation of NF- $\kappa$ B by the Latent vFLIP Gene of Kaposi’s Sarcoma-Associated Herpesvirus Is Required for the Spindle Shape of Virus-Infected Endothelial Cells and Contributes to Their Proinflammatory Phenotype. J Virol https://doi.org/10.1128/jvi.01603-05.

88. Alkharsah KR, Singh V V., Bosco R, Santag S, Grundhoff A, Konrad A, Sturzl M, Wirth D, Dittrich-Breiholz O, Kracht M, Schulz TF. 2011. Deletion of Kaposi's SarcomaAssociated Herpesvirus FLICE Inhibitory Protein, vFLIP, from the Viral Genome Compromises the Activation of STAT1-Responsive Cellular Genes and Spindle Cell Formation in Endothelial Cells. J Virol https://doi.org/10.1128/jvi.00226-11.

89. Yoo J, Kang J, Lee HN, Aguilar B, Kafka D, Lee S, Choi I, Lee J, Ramu S, Haas J, Koh CJ, Hong YK. 2010. Kaposin-B enhances the PROX1 mRNA stability during lymphatic reprogramming of vascular endothelial cells by Kaposi’s sarcoma herpes virus. PLoS 
Pathog https://doi.org/10.1371/journal.ppat.1001046.

90. Chang HC, Hsieh TH, Lee YW, Tsai CF, Tsai YN, Cheng CC, Wang HW. 2016. c-Myc and viral cofactor Kaposin B co-operate to elicit angiogenesis through modulating miRNome traits of endothelial cells. BMC Syst Biol https://doi.org/10.1186/s12918-0150242-3.

91. Aguilar B, Choi I, Choi D, Chung HK, Lee S, Yoo J, Lee YS, Maeng YS, Lee HN, Park reprogramming by Kaposi sarcoma herpes virus promotes the oncogenic activity of the virus-encoded G-protein-coupled receptor. Cancer Res https://doi.org/10.1158/0008-

92. Toth Z, Papp B, Brulois K, Choi YJ, Gao SJ, Jung JU. 2016. LANA-Mediated Recruitment of Host Polycomb Repressive Complexes onto the KSHV Genome during De

93. Gallo A, Lampe M, Günther T, Brune W. 2017. The Viral Bcl-2 Homologs of Kaposi’s Sarcoma-Associated Herpesvirus and Rhesus Rhadinovirus Share an Essential Role for

1125 94. Campbell M, Watanabe T, Nakano K, Davis RR, Lyu Y, Tepper CG, Durbin-Johnson B, Viral Replication. J Virol https://doi.org/10.1128/jvi.01875-16. with domain-specific gene regulation. Nat Commun https://doi.org/10.1038/s41467-01702089-9.

95. West JA, Wicks M, Gregory SM, Chugh P, Jacobs SR, Zhang Z, Host KM, Dittmer DP, Damania B. 2014. An Important Role for Mitochondrial Antiviral Signaling Protein in the 
Kaposi’s Sarcoma-Associated Herpesvirus Life Cycle. J Virol https://doi.org/10.1128/jvi.03226-13.

96. Barbera AJ, Chodaparambil J V., Kelley-Clarke B, Joukov V, Walter JC, Luger K, Kaye KM. 2006. The nucleosomal surface as a docking station for Kaposi's sarcoma herpesvirus LANA. Science (80- ) https://doi.org/10.1126/science.1120541.

97. Hellert J, Weidner-Glunde M, Krausze J, Richter U, Adler H, Fedorov R, Pietrek M, Rückert J, Ritter C, Schulz TF, Lührs T. 2013. A Structural Basis for BRD2/4-Mediated Host Chromatin Interaction and Oligomer Assembly of Kaposi Sarcoma-Associated Herpesvirus and Murine Gammaherpesvirus LANA Proteins. PLoS Pathog https://doi.org/10.1371/journal.ppat.1003640.

98. Vladimirova O, de Leo A, Deng Z, Wiedmer A, Hayden J, Lieberman PM. 2021. Phase separation and DAXX redistribution contribute to LANA nuclear body and KSHV genome dynamics during latency and reactivation. PLoS Pathog https://doi.org/10.1371/journal.ppat.1009231.

99. Lin CL, Li H, Wang Y, Zhu FX, Kudchodkar S, Yuan Y. 2003. Kaposi's SarcomaAssociated Herpesvirus Lytic Origin (ori-Lyt)-Dependent DNA Replication: Identification of the ori-Lyt and Association of K8 bZip Protein with the Origin. J Virol https://doi.org/10.1128/jvi.77.10.5578-5588.2003.

100. Wang Y, Li H, Chan MY, Zhu FX, Lukac DM, Yuan Y. 2004. Kaposi’s SarcomaAssociated Herpesvirus ori-Lyt-Dependent DNA Replication: cis-Acting Requirements for Replication and ori-Lyt-Associated RNA Transcription. J Virol https://doi.org/10.1128/jvi.78.16.8615-8629.2004. 
1153 101. Wang Y, Tang Q, Maul GG, Yuan Y. 2006. Kaposi’s Sarcoma-Associated Herpesvirus ori-Lyt-Dependent DNA Replication: DualRole of Replication and Transcription Activator. J Virol https://doi.org/10.1128/jvi.00990-06.

102. Liu D, Wang Y, Yuan Y. 2018. Kaposi’s Sarcoma-Associated Herpesvirus K8 Is an RNA Binding Protein That Regulates Viral DNA Replication in Coordination with a Noncoding

103. Sharma NR, Majerciak V, Kruhlak MJ, Yu L, Kang JG, Yang A, Gu S, Fritzler MJ, Zheng ZM. 2019. KSHV RNA-binding protein ORF57 inhibits P-body formation to promote viral multiplication by interaction with Ago2 and GW182. Nucleic Acids Res

104. Wang X, Chang L, Wang H, Su A, Wu Z. 2017. Dep1a and GW182 Induce Distinct https://doi.org/10.1093/nar/gkz683. sensors but suppresses downstream transcriptional responses to support lytic replication. PLoS Pathog https://doi.org/10.1371/journal.ppat.1008185. 
Table 1: BAC16 Mutagenesis Primers

\begin{tabular}{|c|c|}
\hline $\begin{array}{l}\text { Primer } \\
\text { Fwd. is forward primer } \\
\text { Rev. is reverse primer }\end{array}$ & $\begin{array}{l}\text { Sequence } \\
\text { Restriction enzyme recognition sites are bolded } \\
\text { BAC16 homology regions are underlined } \\
\text { Complementary target sequences are italicized. }\end{array}$ \\
\hline KanSacB Homology - Fwd. & $\begin{array}{l}\text { 5' ATACATGGATCCAGGATGACGACGATAA } \\
\text { GTAGGGATAACAGGGTAAT 3' }\end{array}$ \\
\hline KanSacB Homology - Rev. & $\begin{array}{l}\text { 5' ATTAGTGCGGCCGCGGACATGAACTGCC } \\
\text { ACAAACACCGTTAAGCCTCTATCCATCAACCAAT } \\
\text { TAACCAATTCTGAT }{ }^{\prime}\end{array}$ \\
\hline altKapC Homology - Fwd. & $\begin{array}{l}\text { 5' ATACATGCTAGCCGGAGGACGGATCTCT } \\
\text { TGGATTTACACGTATCGAGGAGCGGTAGCACCC } \\
\text { CAGGAACCCGTCCTAGCACACCCCA 3' }\end{array}$ \\
\hline altKapC Homology - Rev. & $\begin{array}{l}\text { 5' TGATTAGGATCCGGACATGAACTGCCAC } \\
\text { AAACACCGTTAAGCCTCTATCCATACACTGAGAT } \\
T G A A G A G 3^{\prime}\end{array}$ \\
\hline altKapB Homology - Fwd. & $\begin{array}{l}\text { 5' ATACATGCTAGCCGGAGGACGGATCTCT } \\
\text { TGGATTTACACGTATCGAGGAGCGGTGGCACCC } \\
C A G G A A C C C G T \text { 3' }\end{array}$ \\
\hline altKapB Homology - Rev. & $\begin{array}{l}\text { 5' TGATTAGGATCCGGACATGAACTGCCAC } \\
\text { AAACACCGTTAAGCCTCTATCCATGCATAGGTAT } \\
\text { AGGTGGTAGA 3' }\end{array}$ \\
\hline Kaposin Screening - Fwd. & 5' CAGGAAACGCTATAAAGAAGAGG 3' \\
\hline
\end{tabular}




\begin{tabular}{|l|l|}
\hline Kaposin Screening - Rev. & $5^{\prime}$ ACAGACAAACGAGTGGTGGTATC $3^{\prime}$ \\
\hline altKapC Screening - Rev. & $5^{\prime}$ ATTACCTGGAAGCAATGCACC 3' \\
\hline altKapB Screening - Rev. & $5^{\prime}$ TGATGAAGGAACTAGATTGCCAG 3' \\
\hline $\begin{array}{l}\text { KanSacB Screening - Fwd. } \\
\text { Revertant Screening - Rev. }\end{array}$ & $5^{\prime}$ GCGACAACCATACGCTGAGAG 3' \\
\hline $\begin{array}{l}\text { Homology primer) } \\
\text { (Revertant Screening - Rev. }\end{array}$ & $5^{\prime}, \underline{\text { TCACCGTTAAGCCTCTATCCAT 3' }}$ \\
\hline
\end{tabular}


Table 2: Antibodies

\begin{tabular}{|c|c|c|c|c|}
\hline Antibody & Species & $\begin{array}{l}\text { Vendor/Catalogue } \\
\#\end{array}$ & Application & Dilution \\
\hline Hedls & Mouse & $\begin{array}{l}\text { Santa-Cruz } \\
\text { sc- } 8418\end{array}$ & Immunofluorescence & $1: 1000$ \\
\hline KapB & Rabbit & $\begin{array}{l}\text { A generous gift } \\
\text { from Don Ganem }\end{array}$ & Immunoblot & $1: 1000$ \\
\hline LANA & Rabbit & $\begin{array}{l}\text { A generous gift } \\
\text { from Don Ganem }\end{array}$ & $\begin{array}{l}\text { Immunofluorescence } \\
\text { Immunoblot }\end{array}$ & $\begin{array}{l}1: 1000 \\
1: 1000\end{array}$ \\
\hline $\begin{array}{l}\text { Alexa Fluor }{ }^{\mathrm{TM}} \\
647 \text { Phalloidin }\end{array}$ & N/A & $\begin{array}{l}\text { Thermo Fisher } \\
\text { A22287 }\end{array}$ & Immunofluorescence & $1: 100$ \\
\hline $\begin{array}{l}\text { Alexa Fluor }{ }^{\mathrm{TM}} \\
488\end{array}$ & $\begin{array}{l}\text { Chicken anti- } \\
\text { Rabbit }\end{array}$ & $\begin{array}{l}\text { Thermo Fisher } \\
\text { A-21441 }\end{array}$ & Immunofluorescence & $1: 1000$ \\
\hline $\begin{array}{l}\text { Alexa Fluor }{ }^{\mathrm{TM}} \\
647\end{array}$ & $\begin{array}{l}\text { Chicken anti- } \\
\text { Mouse }\end{array}$ & $\begin{array}{l}\text { Thermo Fisher } \\
\text { A-21463 }\end{array}$ & Immunofluorescence & $1: 1000$ \\
\hline Hoechst 33342 & $\mathrm{~N} / \mathrm{A}$ & $\begin{array}{l}\text { Thermo Fisher } \\
\text { H3570 }\end{array}$ & Immunofluorescence & $1: 10000$ \\
\hline $\begin{array}{l}\text { Beta-Actin } \\
\text { HRP } \\
\text { Conjugate }\end{array}$ & Rabbit & $\begin{array}{l}\text { Cell Signaling } \\
\text { Technologies } \\
5125\end{array}$ & Immunoblot & $1: 8000$ \\
\hline $\begin{array}{l}\text { Anti-rabbit } \\
\text { IgG HRP- } \\
\text { linked }\end{array}$ & N/A & $\begin{array}{l}\text { Cell Signaling } \\
\text { Technologies } \\
7074\end{array}$ & Immunoblot & $1: 3000$ \\
\hline
\end{tabular}


Table 3: qPCR primers

\begin{tabular}{|c|c|}
\hline Primer & Sequence \\
\hline ORF26 - Forward & 5' CAGTTGAGCGTCCCAGATGA 3' \\
\hline ORF26 - Reverse & 5' GGAATACCAACAGGAGGCCG 3' \\
\hline$\beta$-actin-Forward & 5' CTTCCAGCAGATGTGGATCA 3' \\
\hline$\beta$-actin - Reverse & 5' AAAGCCATGCCAATCTCATC 3' \\
\hline Luc-Forward & 5' TGCGCAAGAATAGCTCCTCC 3' \\
\hline Luc-Reverse & 5' TTCGGCAACCAGATCATCCC 3' \\
\hline IL-6 - Forward & 5' GTCCAGTTGCCTTCTCCCTGG 3' \\
\hline IL-6 - Reverse & 5' GAGATGCCGTCGAGGATGTACC 3' \\
\hline CSF2 - Forward & 5' AAATGTTTGACCTCCAGGAGCC 3' \\
\hline CSF2 - Reverse & 5' ATCTGGGTTGCACAGGAAGTT 3' \\
\hline VEGFA - Forward & 5' CGAGACCTTGGTGGACATC 3' \\
\hline VEGFA - Reverse & 5' CTGCATGGTGACGTTGAAC 3' \\
\hline IL-1 $\beta$ - Forward & 5' СТСТСАССТСТССТАСТСАСТТ 3' \\
\hline IL-1 $\beta$ - Reverse & 5' TCAGAATGTGGGAGCGAATG 3' \\
\hline LANA - Forward & 5' GCGAAGGAAGCATGTCGCC 3' \\
\hline LANA - Reverse & 5' CACAGGATGGGATGGAGGGATTG 3' \\
\hline $18 \mathrm{~S}-$ Forward & 5' CGTTCTTAGTTGGTGGAGCG 3' \\
\hline $18 \mathrm{~S}-$ Reverse & 5' CCGGACATCTAAGGGCATCA 3' \\
\hline HPRT-1 - Forward & 5' TGGCGTCGTGATTAGTGATG 3' \\
\hline HPRT-1 - Reverse & 5' GACGTTCAGTCCTGTCCATAAT 3' \\
\hline
\end{tabular}


Table 4: Plasmids

\begin{tabular}{|c|c|c|c|}
\hline Plasmid & Use & Source & $\begin{array}{l}\text { Mammalian } \\
\text { Selection }\end{array}$ \\
\hline pcDNA3.1 $(+)$ & $\begin{array}{l}\text { Empty Vector } \\
\text { Control }\end{array}$ & Invitrogen V79020 & N/A \\
\hline $\begin{array}{l}\text { pcDNA3.1 KapB KS } \\
\text { lung }\end{array}$ & Overexpression & $\begin{array}{l}\text { C. McCormick } \\
\text { (Dalhousie } \\
\text { University) }\end{array}$ & $\mathrm{N} / \mathrm{A}$ \\
\hline $\begin{array}{l}\text { pcDNA3.1 KapB } \\
\text { BAC16 }\end{array}$ & Overexpression & $\begin{array}{l}\text { Cloned from pUC57 } \\
\text { KapB BAC16 (Bio } \\
\text { Basic) }\end{array}$ & N/A \\
\hline pLJM1 & $\begin{array}{l}\text { Empty Vector } \\
\text { Control }\end{array}$ & (105) & Blasticidin \\
\hline $\begin{array}{l}\text { pLJM1 KapB } \\
\text { (pulmonary KS) }\end{array}$ & Overexpression & $\begin{array}{l}\text { Cloned from } \\
\text { pBMNIP-KapB (51) } \\
\text { into pLJM1-BSD }\end{array}$ & Blasticidin \\
\hline pMD2.G & Lentivirus generation & Addgene \#12259 & $\mathrm{N} / \mathrm{A}$ \\
\hline psPAX2 & Lentivirus generation & Addgene \#12260 & $\mathrm{N} / \mathrm{A}$ \\
\hline
\end{tabular}


Figure 1. Lambda Red recombination facilitates the creation of five kaposin-deficient

BAC16 DNA constructs. (A) A simplified version of the kaposin transcript is depicted in the 5' isolated from GS1783 E.coli harbouring recombinant or WT BAC16 DNA and then subjected to whole genome sequencing (WGS). Raw reads were paired, trimmed, and mapped to the BAC16

1221 genome (NCBI accession \#GQ994935) in Geneious Prime. Coverage for each recombinant is

1222 indicated in blue with an average coverage per nucleotide of between 670-1430x. BAC16 ORFs

1223 are depicted in turquoise, repeat regions in orange and the kaposin locus is outlined in red.

1224 Variants were detected based on a minimum coverage of 5 and minimum frequency variation of

12250.25 and are depicted in magenta. (B) Representative zoom panels of read alignment to the

1226 kaposin locus of WT and $\triangle \mathrm{KapB}$ are shown. (C) BAC16 DNA was isolated from GS1783 E.coli

1227 and digested using NheI and fragments were subjected to pulsed-field gel electrophoresis 
1228 (PFGE). Based on in silco predictions, kaposin locus containing fragments are indicated with a

1229 red asterisk.

1241 hygromycin (increasing concentration from $200 \mu \mathrm{g} / \mathrm{mL}$ to $1200 \mu \mathrm{g} / \mathrm{mL}$ ) until a confluent layer of

1242 BAC16-containing iSLK cells was achieved (E). Latent iSLKs were fixed, permeabilized and

1243 immunostained using antisera for viral LANA (green) to visualize infected nuclei and Hoescht to

1244 visualize total cell nuclei (blue). Images were captured using Zeiss AxioObserver Z1 microscope

1245 with the $40 \mathrm{X}$ objective. Scale bar $=20 \mu \mathrm{m}$. (F) BAC16-containing iSLKs were trypsinized,

1246 pelleted and lysed to extract DNA. qPCR was performed using ORF26 and $\beta$-actin specific

1247 primers. Values are represented as fold change relative to WT. $n=3$; mean $\pm \mathrm{SD},(*, \mathrm{P}<0.05 ; * *$,

$1248 \mathrm{P}<0.01 ; * * *, \mathrm{P}<0.001 ; * * * *, \mathrm{P}<0.0001$; ns, nonsignificant). 

wild-type (WT) BAC16 iSLK cells at passages 1 (P1) $n=3$; means $\pm \mathrm{SD},(*, \mathrm{P}<0.05 ; * *, \mathrm{P}<$

1257 change relative to the corresponding starting passage (P1), for each recombinant virus over the 1258 course of the experiment. $n=3$; mean \pm SD. The red line was obtained using linear regression 1259 analysis and the slope of the line is depicted in the top right corner for each graph.

Figure 5. Kaposin-deficient BAC16 iSLK cells produce progeny virions when reactivated. immunoblotting using antisera that recognizes DR1 in both KapB and KapC. Specific antibody

1267 performed using ORF26 and host $\beta$-actin specific primers. Values represent either fold-change

1268 relative to time 0 (latency) for each recombinant virus (B) $n=3$, mean $\pm \mathrm{SD}$, or fold-change

1269 relative to $\mathrm{WT}$ at $0,24,48,72$ and $96 \mathrm{~h}$ post reactivation, $(\mathrm{C}) n=3$; mean $\pm \mathrm{SD},(*, \mathrm{P}<0.05 ; * *, \mathrm{P}$

$1270<0.01 ; * * *, \mathrm{P}<0.001 ; * * * *, \mathrm{P}<0.0001$; ns, nonsignificant). (D). BAC16-iSLK cells were

1271 reactivated as above for 96h, virus-containing supernatant was collected, clarified and DNase-

1272 treated prior to extraction of virion-protected DNA. qPCR was performed using ORF26 and 
1273 luciferase (control) specific primers. Values represented fold-change relative to WT. $n=3$; mean

$1274 \pm \mathrm{SD},\left(^{*}, \mathrm{P}<0.05 ; * *, \mathrm{P}<0.01 ; * * *, \mathrm{P}<0.001 ; * * * *, \mathrm{P}<0.0001 ;\right.$ ns, nonsignificant). (E)

1275 BAC16-iSLK cells were reactivated for 96 hours. Virus-containing supernatant for each

1276 recombinant cell line was then collected, clarified, and diluted 1:4 with fresh DMEM and used to

1277 infect naïve 293T cells. After 24h, cells were fixed, permeabilized and stained using antisera

1278 specific for viral LANA (green) and Hoescht (nucleus, blue). Images were captured using Zeiss

1279 AxioObserver Z1 microscope with the $40 \mathrm{X}$ objective. Scale bar $=20 \mu \mathrm{m}$. One representative

1280 experiment is shown.

1283 (A-B) Equal numbers of virus particles (based on DNase-protected extracellular genome copy 1284 number) of WT and either $\triangle \mathrm{KapB}-1$ and $\triangle \mathrm{KapB}-2$ were used to infect HUVECs. 24h later, cells 1285 were fixed, permeabilized and immunstained for viral LANA, then stained with Hoescht. The 1286 number of LANA-expressing cells was quantified and is represented as a percent of the total 1287 number of cells counted. $n=2$; mean \pm SD. (C) Images of four different $\Delta$ KapB BAC16-iSLK 1288 latent cell lines and WT BAC16-iSLKs were captured using an EVOS-FL microscope with the 1289 10X objective. One representative experiment of two is shown. (D-F) Latent $\Delta \mathrm{KapB}$ and WT 1290 BAC16-iSLKs were fixed, permeabilized and immunostained for viral LANA, then stained with 1291 Hoescht. LANA-NBs were visualized (D), and the number of LANA-NBs per cell was counted 1292 using CellProfiler (E) $n=2$; mean \pm SD. LANA-NB area was calcuated for at approximently 4000 1293 individual LANA-NBs per cell line and the distribution of area shown in (F). (G) Latent $\Delta$ KapB 1294 and WT BAC16-iSLKs were trypsinized, pelleted and lysed to extract DNA. qPCR was 1295 performed using ORF26 and $\beta$-actin specific primers. Values are represented as fold change 
relative WT. $n=3$, mean $\pm \mathrm{SD},(*, \mathrm{P}<0.05 ; * *, \mathrm{P}<0.01$; ***, $\mathrm{P}<0.001 ; * * * *, \mathrm{P}<0.0001$; ns, nonsignificant). (H) Latent BAC16-iSLKs were lysed and harvested for immunoblotting using LANA and $\beta$-actin specific antibodies. One representative experiment of two is shown.

\section{Figure 7. Ectopic expression of KapB does not rescue altered latency phenotypes in $\Delta K a p B$}

infected cells. (A-C) Latent WT or $\triangle \mathrm{KapB}$ BAC16-iSLK cells lines were transduced to express either an empty vector (EV) control or KapB (KS lung isolate). 24h later, cells were selected using blasticidin for $48 \mathrm{~h}$ prior to seeding. The following day seeded cells were lysed and harvested for RNA or protein analysis. (A-B) RT-qPCR was performed using LANA and 18S specific primers. $n=3$; mean $\pm \mathrm{SD},(*, \mathrm{P}<0.05 ; * *, \mathrm{P}<0.01 ; * * *, \mathrm{P}<0.001 ; * * * *, \mathrm{P}<0.0001$; ns, nonsignificant). In A, LANA RNA transcript levels in $\triangle \mathrm{KapB}$ iSLK cell lines are shown normalized to WT iSLK cells. In B, LANA RNA transcript levels are shown after KapB complementation, normalized to each respective EV control. (C) Immunoblotting was performed using LANA, DR1 (KapB) and $\beta$-actin specific antibodies. One representative experiment of three is shown. (D-F) Naïve iSLK cells were transduced with EV or KapB lentiviruses as in (A). After seeding, cells were infected with equal particle numbers of WT and $\triangle \mathrm{KapB}$ BAC16 viruses as determined via DNase-protected extracellular genome copy number. $24 \mathrm{~h}$ post infection, cells were either trypsinized, pelleted and lysed to extract DNA or lysed for immunoblotting. (D-E) qPCR was performed for KSHV DNA using ORF26 and host $\beta$-actin specific primers. $n=3$; mean $\pm \mathrm{SD},(*, \mathrm{P}<0.05 ; * *, \mathrm{P}<0.01 ; * * *, \mathrm{P}<0.001 ; * * * *, \mathrm{P}<0.0001$; ns, nonsignificant). In D, Viral genome copy number for iSLKs after de novo infection with $\Delta \mathrm{KapB}$ is normalized to the WT control. In E, viral genome copy number for each virus infection after complementing with $\mathrm{KapB}$ is normalized to each respective EV control. (F) 
1319 representative experiment of three is shown. (G-I) 293T cells were transfected with three

1320 different ectopic expression constructs for KapB: KapB derived from KS lung (45) and KapB

1321 BAC16. $24 \mathrm{~h}$ after transfection, cells were infected with equal particle numbers of WT and

$1322 \Delta \mathrm{KapB}$ BAC16 viruses and processed as above for $\mathrm{qPCR}\left(\mathrm{G}-\mathrm{H}, n=3\right.$; mean $\pm \mathrm{SD},\left(^{*}, \mathrm{P}<0.05\right.$;

$1323 * *, \mathrm{P}<0.01 ; * * *, \mathrm{P}<0.001 ; * * * *, \mathrm{P}<0.0001$; ns, nonsignificant). or immunoblotting (I, $\mathrm{n}=1)$.

1324 In G, Viral genome copy number for 293Ts after de novo infection with $\Delta$ KapB is normalized to

1325 the WT control. In H, viral genome copy number for each virus infection after complementing

1326 with different versions of KapB is normalized to each respective EV control.

1327 Figure 8. KapB is required for PB disassembly following de novo HUVEC infection. (A)

1328 WT and $\triangle \mathrm{KapB} B A C 16$ viruses were titrated using $293 \mathrm{~T}$ cells and RFP expression was used to

1329 estimate an equal number of infectious virions for subsequent de novo infection of HUVECs. At

1330 96hpi, HUVECs were fixed, permeabilized and immunostained for either viral LANA (green),

1331 the PB-resident protein Hedls/EDC4 (white) then stained with Hoescht (nucleus, blue). Images

1332 were captured using Zeiss AxioObserver Z1 microscope with the 40X objective. Scale bar $=20$

$1333 \mu \mathrm{m}$. (B) Hedls puncta per cell were quantified using CellProfiler. For mock infections, all cells

1334 were counted; for WT and $\Delta \mathrm{KapB}$-infected cells, only LANA-positive cells were counted. Data 1335 is represented as fold change in PBs per cell relative to mock infection. $n=4$; mean $\pm \mathrm{SD},(*, \mathrm{P}<$ $13360.05 ; * *, \mathrm{P}<0.01 ; * * *, \mathrm{P}<0.001 ; * * * *, \mathrm{P}<0.0001$; ns, nonsignificant). (C) Cells infected as in

1337 (A) were lysed at 96 hpi and harvested for immunoblotting using LANA, DR1 (KapB and C) and

$1338 \beta$-actin specific antibodies. One representative experiment of three is shown. (D) Cells infected

1339 as in (A) were lysed at 96 and 120 hpi and harvested for RNA extraction and RT-qPCR using IL-

1340 6, CSF2, VEGFA, IL-1 $\beta$ and HPRT specific primers. $n=3$; mean $\pm \mathrm{SD},(*, \mathrm{P}<0.05 ; * *, \mathrm{P}<$

$1341 \quad 0.01 ; * * *, \mathrm{P}<0.001 ; * * * *, \mathrm{P}<0.0001 ;$ ns, nonsignificant). 
1342 Figure 9 KapB is not required for endothelial cell spindling following de novo HUVEC

1343 infection. WT and $\triangle \mathrm{KapB} B A C 16$ viruses were titrated using $293 \mathrm{~T}$ cells and RFP expression

1344 was used to estimate an equal number of infectious virions for subsequent de novo infection of

1345 HUVECs, as in Figure 8. At 96 hpi, brightfield images were acquired at 10X, cells were fixed,

1346 permeabilized and immunostained for viral LANA (green). Phalloidin and Hoescht staining was

1347 used to visualize actin (white) and nuclei (blue), respectively. Images were captured using Zeiss

1348 AxioObserver Z1 microscope with the $40 \mathrm{X}$ objective. Scale bar $=20 \mu \mathrm{m}$. One representative

1349 image of three experiments is shown. 
bioRxiv preprint doi: https://doi.org/10.1101/2021.06.11.448153; this version posted September 7,2021 . The copyright holder for this preprint (which was not certified by peer review) is the author/funder, who has granted bioRxiv a license to display the preprint in perpetuity. It is made

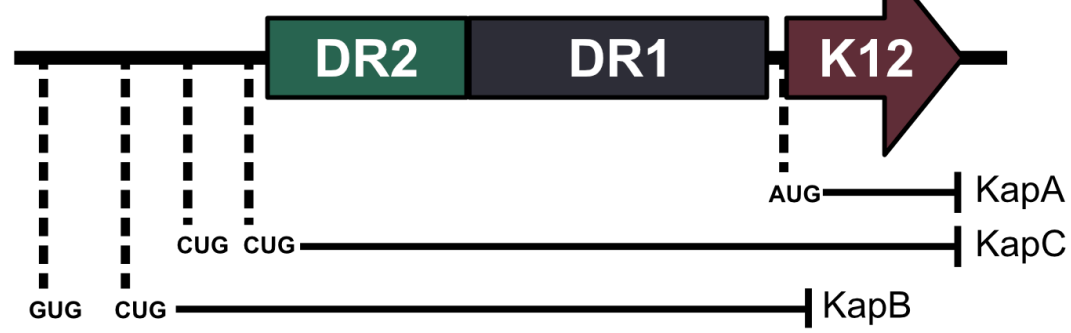

B

Wild-type (WT)

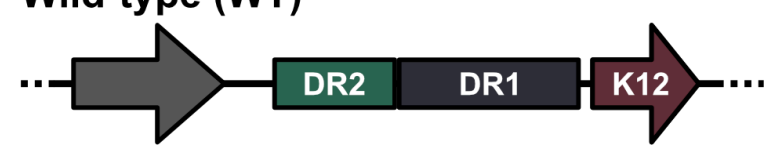

$\triangle$ KapABC

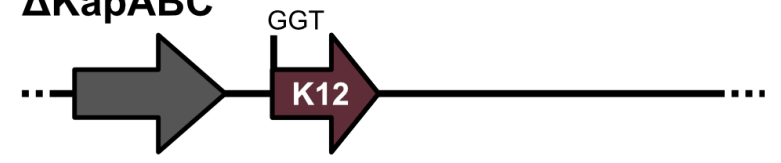

$\Delta$ KapBC

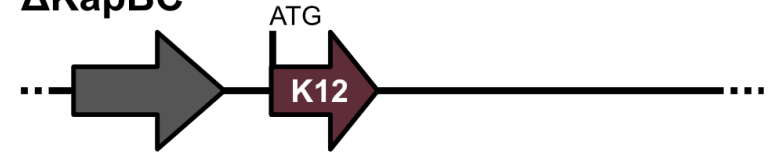

$\Delta$ KapB

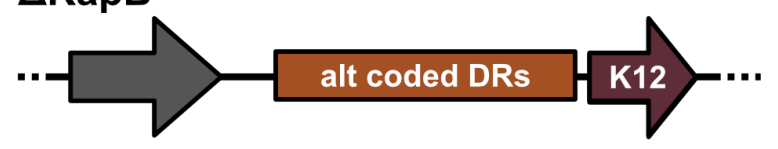

$\Delta \mathrm{KapC}$

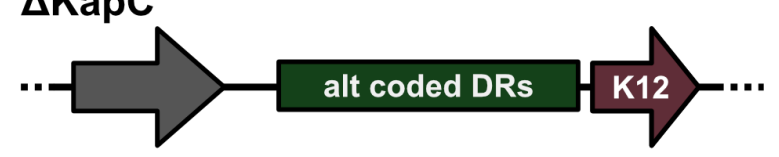

BAC16

BAC16

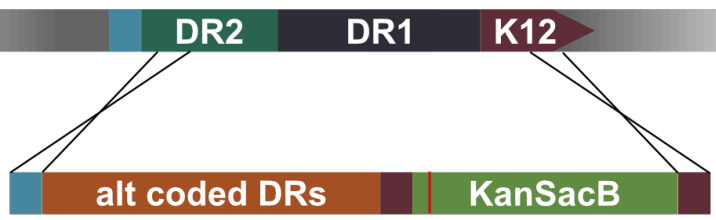

First lambda red recombination

Kanamycin selection

\section{\begin{tabular}{|l|l|l|}
\hline alt coded DRs & KanSacB & K12 \\
\hline
\end{tabular}}

BAC16

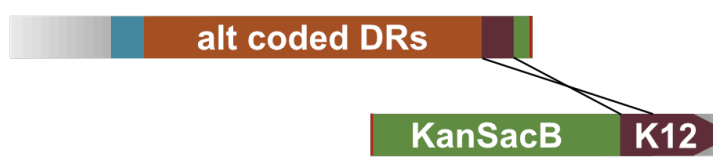

Second lambda red recombination Sucrose selection

\section{alt coded DRs K12}

D

$\triangle$ KapB BAC16 Generation - First Recombination

$3.9 \mathrm{~kb}$

$\stackrel{0.8 \mathrm{~kb} \rightarrow}{\longrightarrow} \stackrel{0.8 \mathrm{~kb}}{\longrightarrow}$

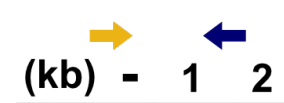

3.0

1.0

$0.5-$
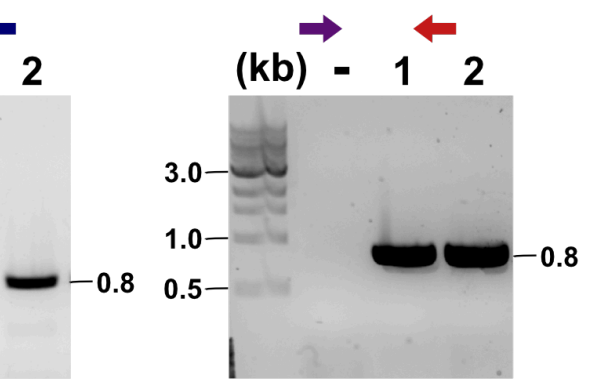

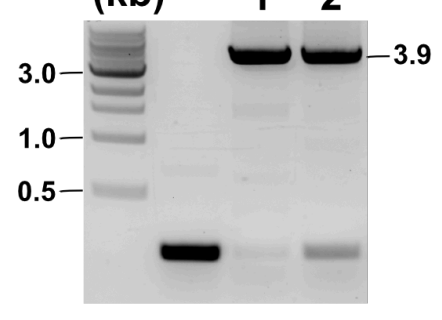

$\triangle$ KapB BAC16

Second Recombination
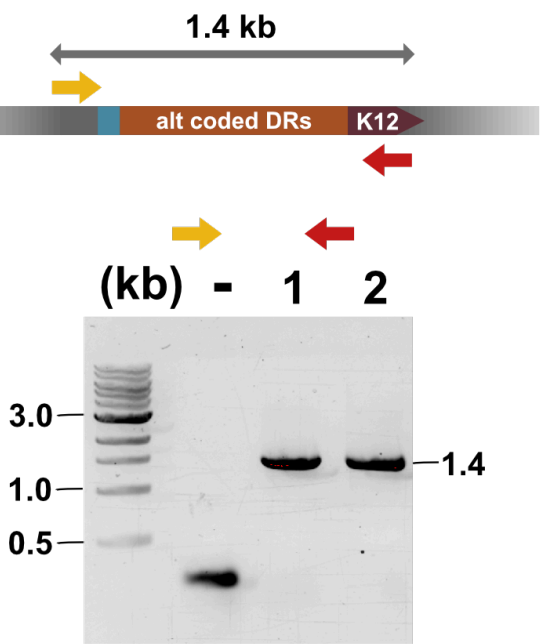
$\Lambda$ bioRxiv preprint doi: https://doi.org/10.1101/2021.06.11.448153; this version posted September 7, 2021. The copyright holder for this preprint Wilieh-ty

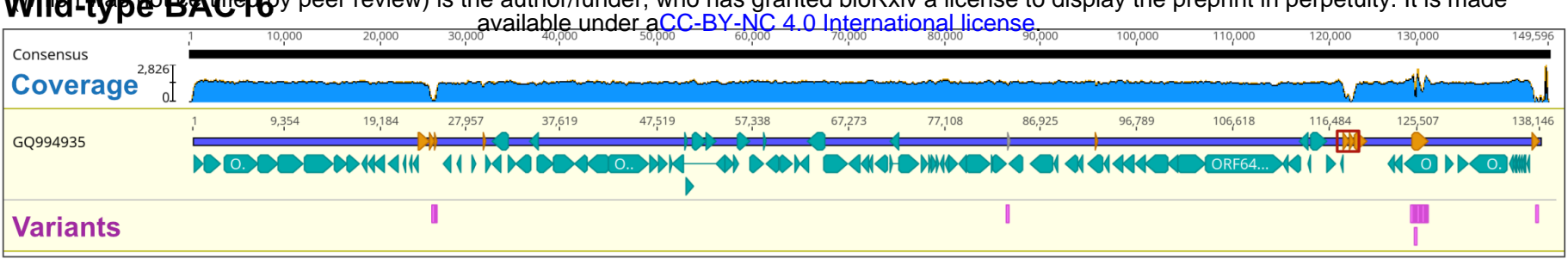

\section{BAC 16 $\triangle$ KapABC}

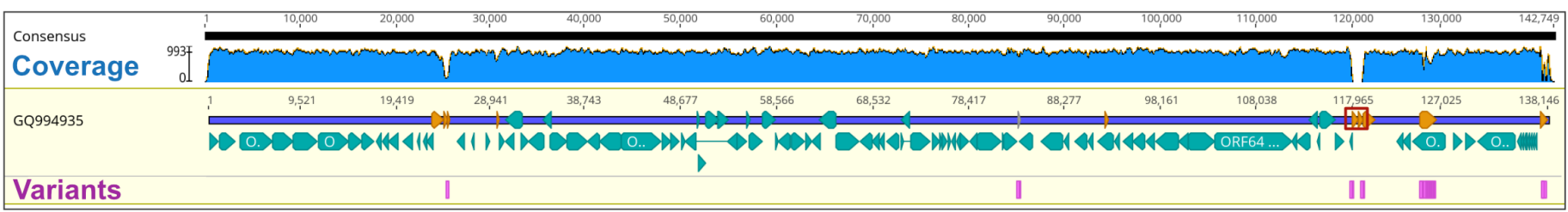

\section{BAC16 $\triangle K a p B C$}

Consensus

Coverage

GQ994935

Variants

(20,000

\section{BAC16 KapB}

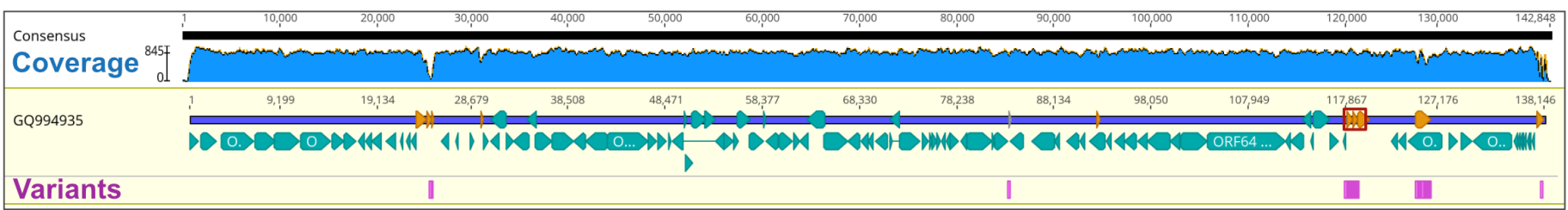

\section{BAC16 KKapC}

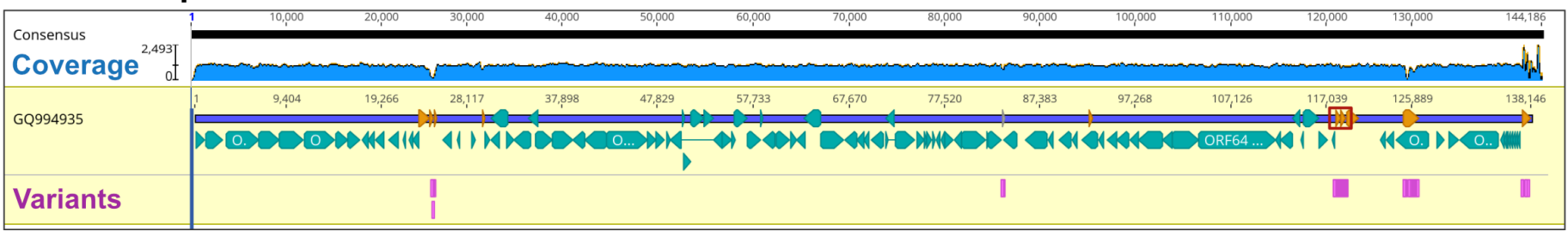

B

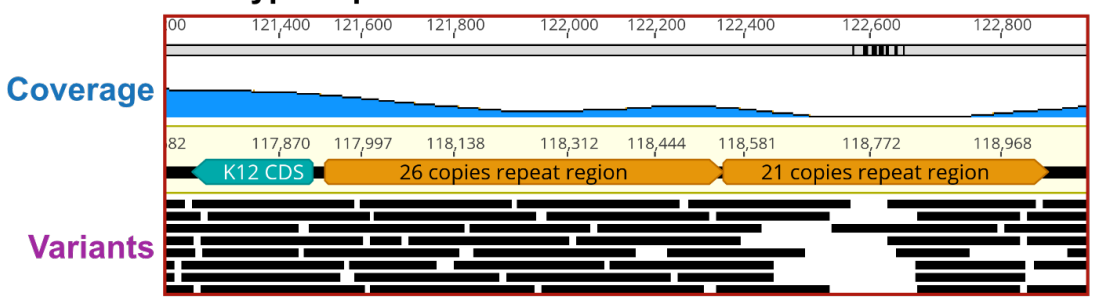

\section{BAC16 $\triangle$ KapB kaposin}

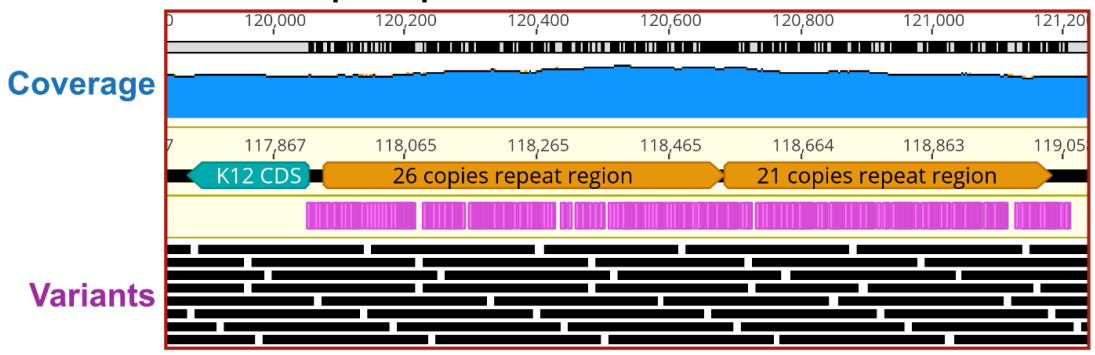

Nhe-I

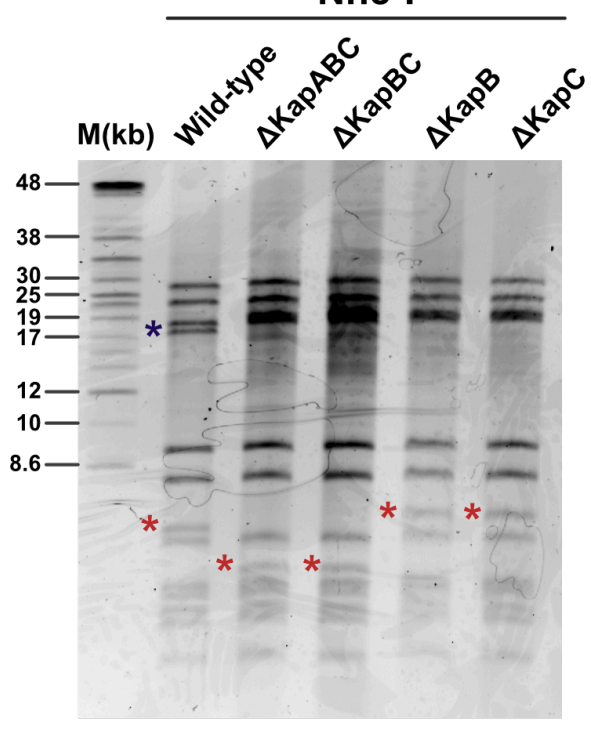




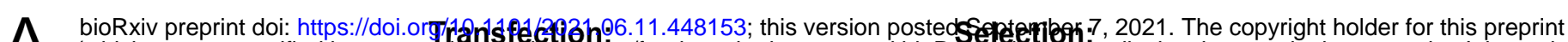

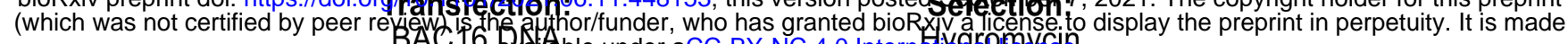
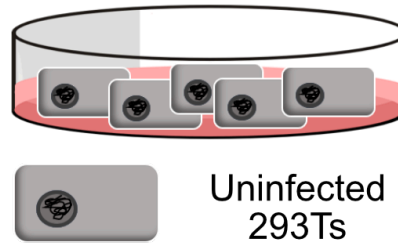

B

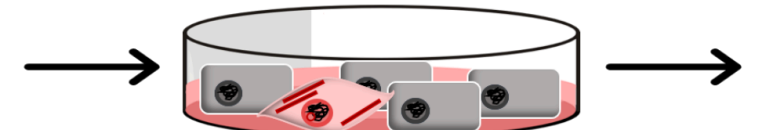

Latent

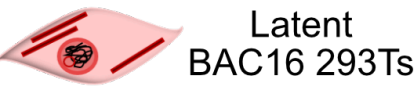

Uninfected

(293Ts

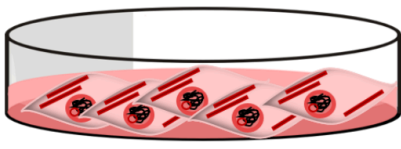

Latent

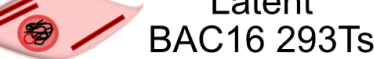

Latent BAC16 293Ts
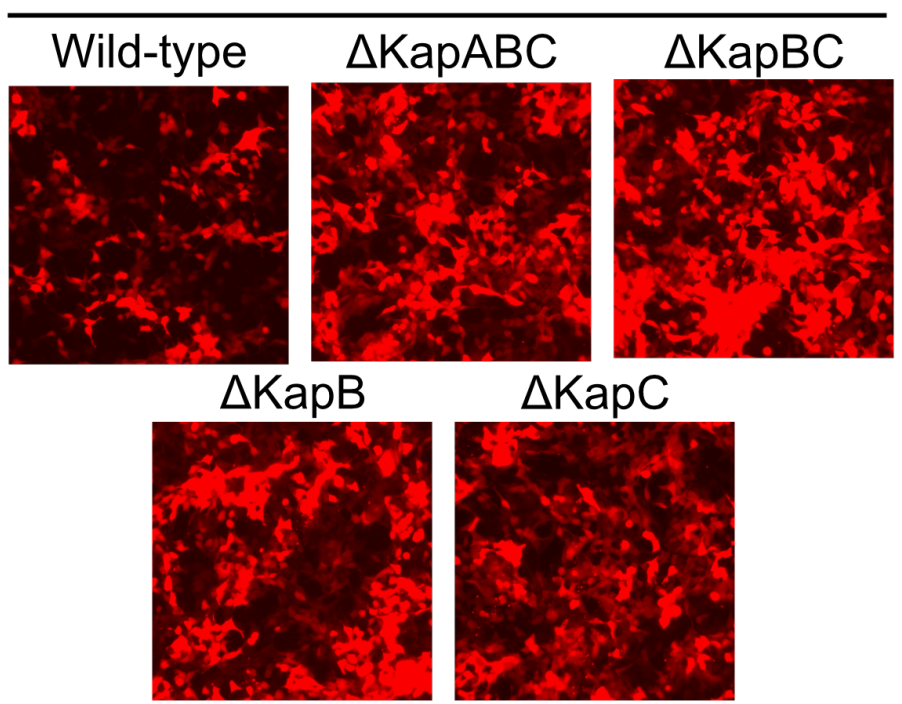

$\Delta \mathrm{KapC}$

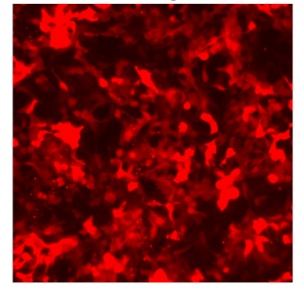

C

Intracellular genomes

(Latency)

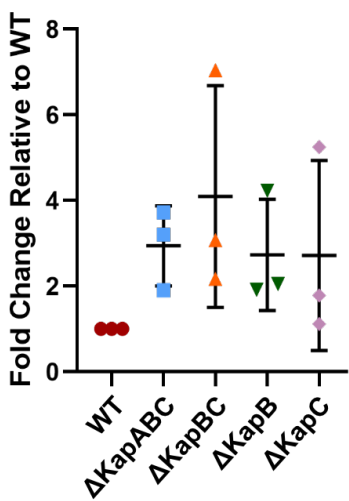

$\mathrm{D}$

Reactivation:

NaB \& TPA

Selection:

Hygromycin \& Puromycin

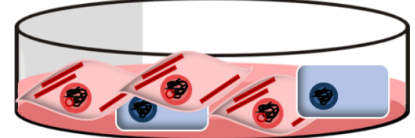

Latent

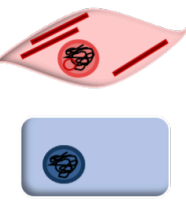

BAC16 293Ts

Uninfected iSLK TREX-RTA

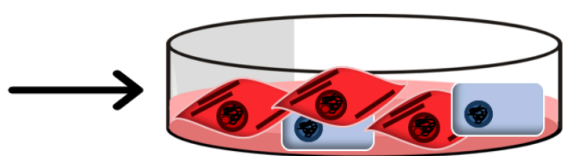

Lytic

BAC16 293Ts

Uninfected iSLK TREx-RTA

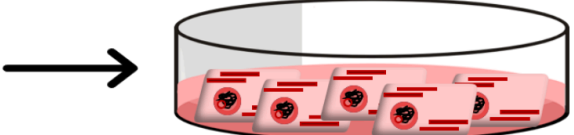

(2)
Latent

BAC16 iSLK TREx-RTA

E

Latent BAC16 iSLKs

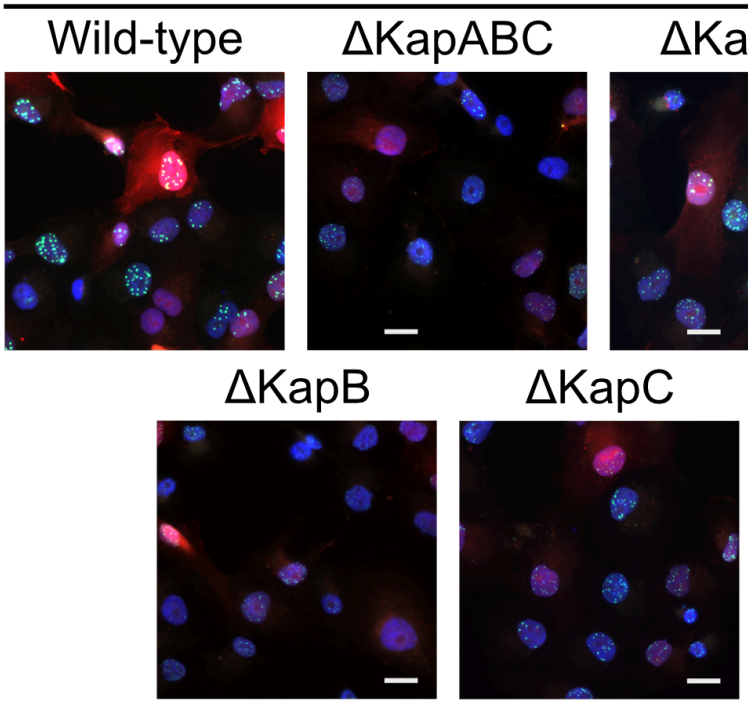

RFP/LANA/Hoechst

Intracellular genomes

(Latency)

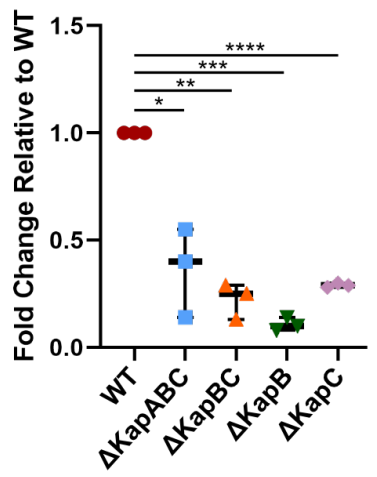


bioRxiv preprint doi: https://doi.org/10.1101/2021.06.11.448153: this version posted September 7, 2021. The copyright holder for this preprint (which was not certified by peer review) is the author/funder, who has granted bioRxiv a license to display the preprint in perpetuity. It is made available under aCC-BY-NC 4.0 International license.

A

Intracellular genomes

(P1)
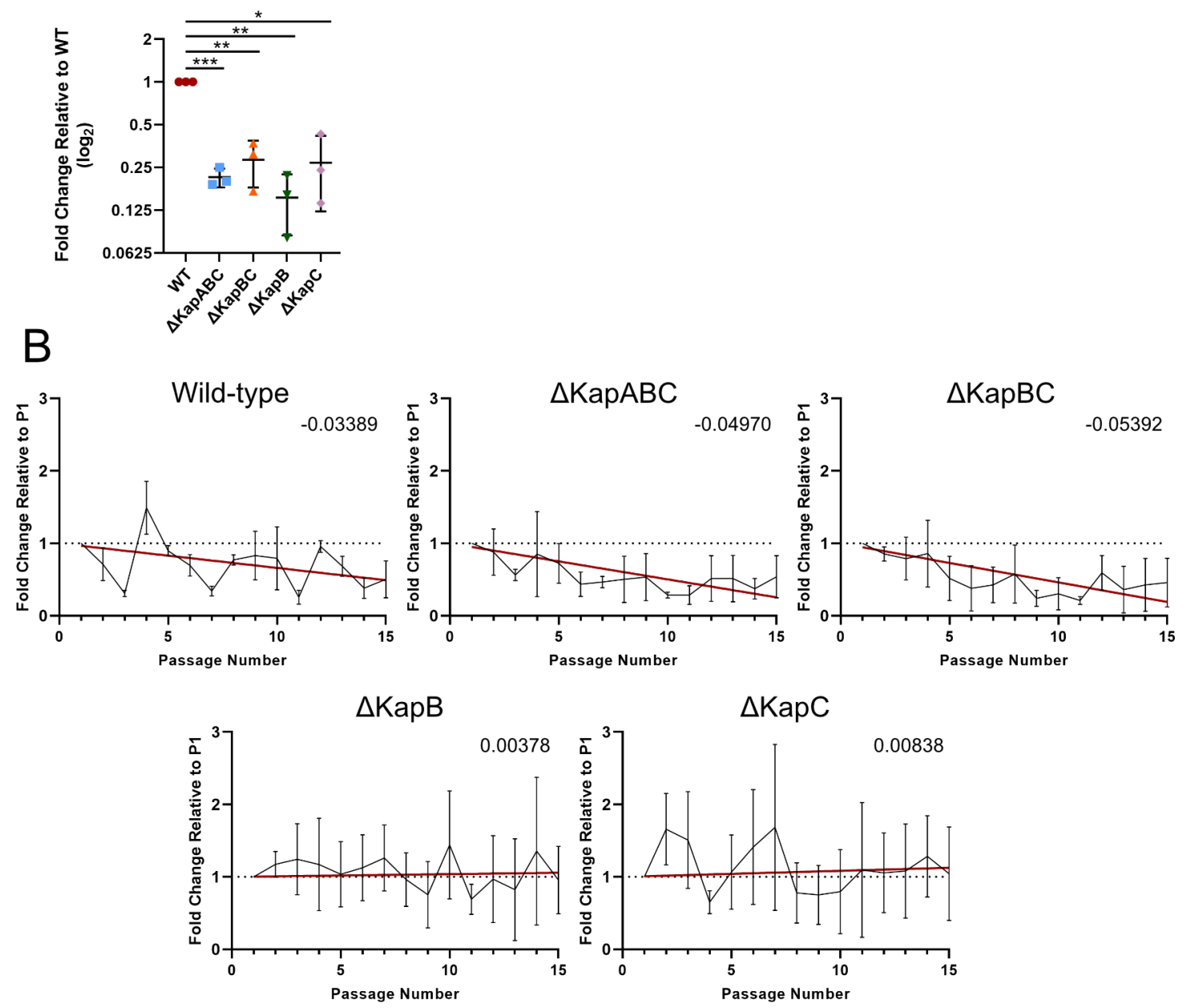
A

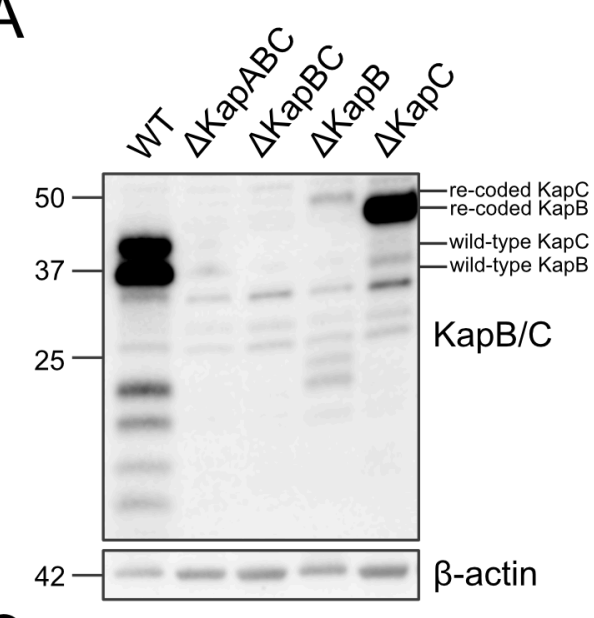

C

Latent

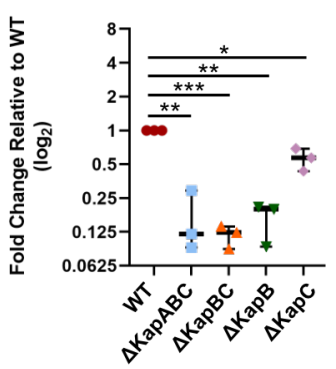

48 hours

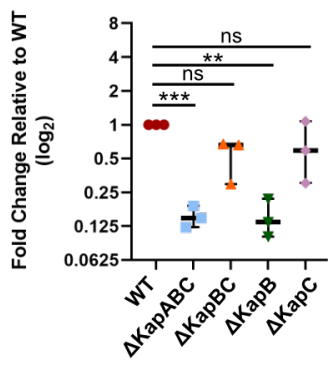

96 hours

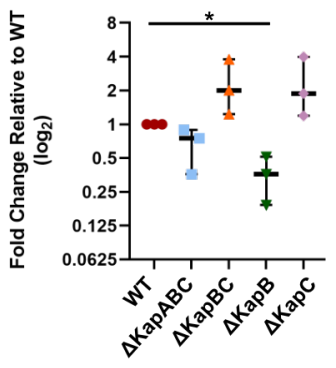

B
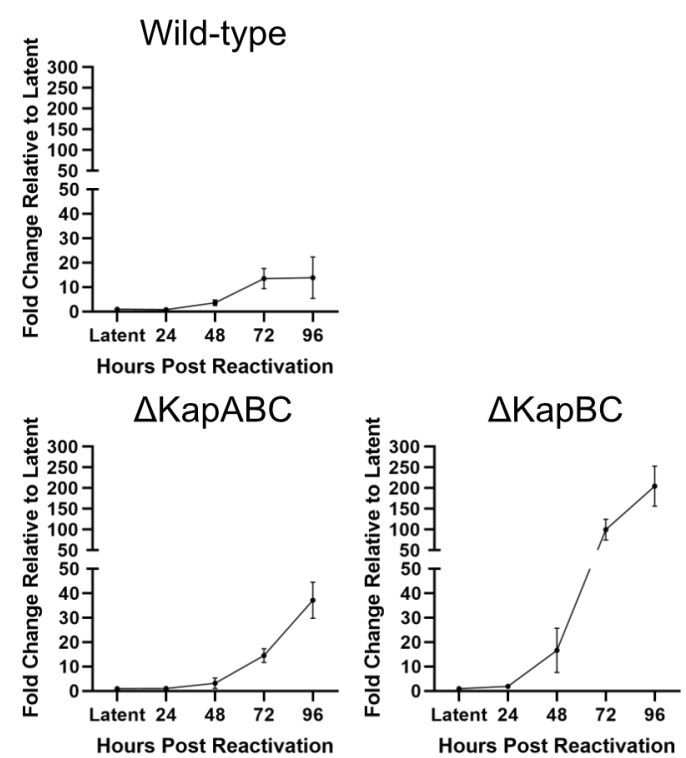

24 hours

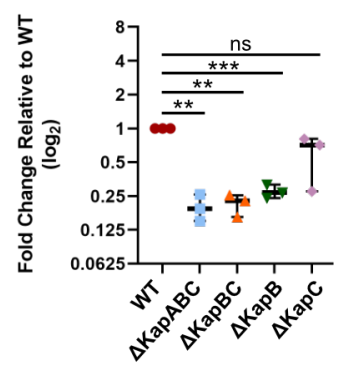

72 hours

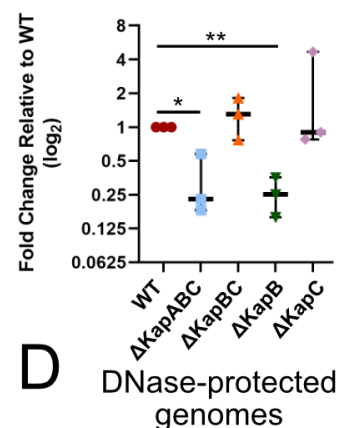
genomes

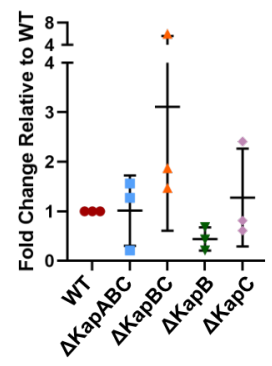

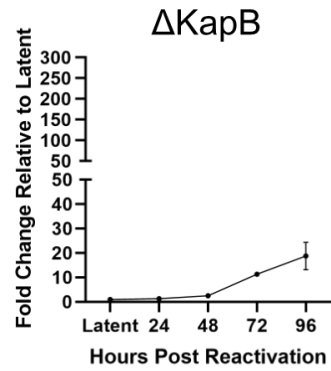

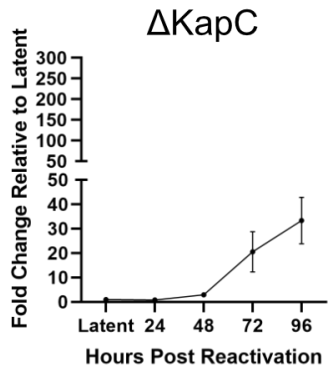

$E$

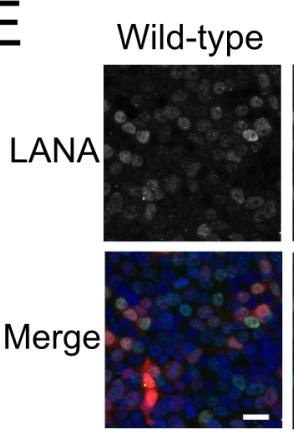

$\triangle \mathrm{KapABC}$

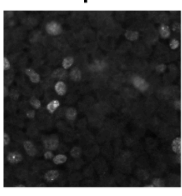

$\triangle \mathrm{KapBC}$
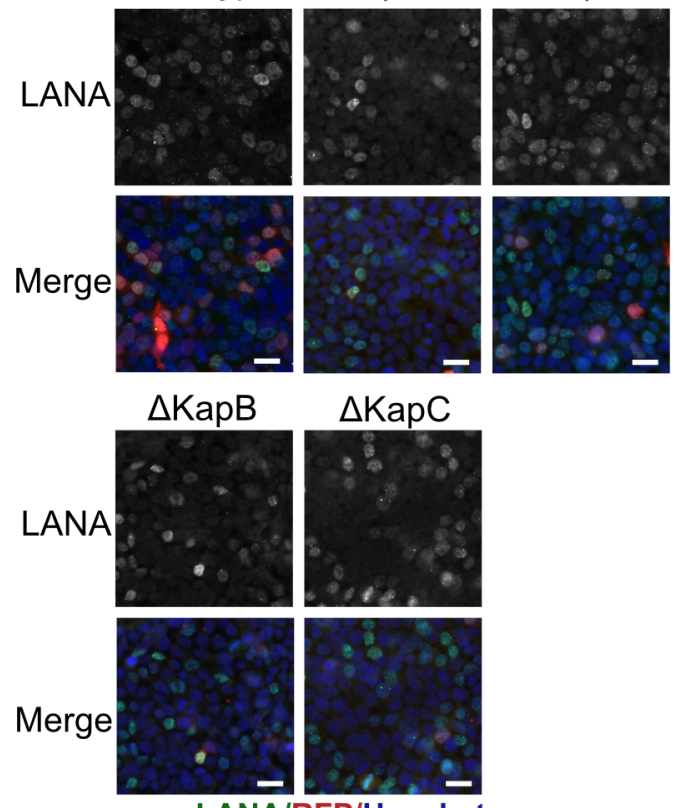

LANA/RFP/Hoechst 
bioRxiv preprint doi

A (which was not certi 0 by peer review) is the author/funder, who has granted bioRxiv a license to display the preprint in perpetuity. It is made
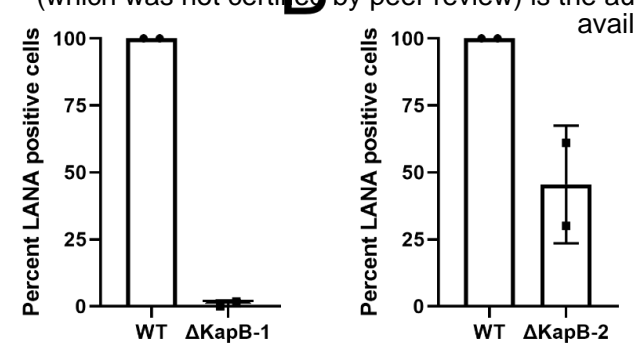

C
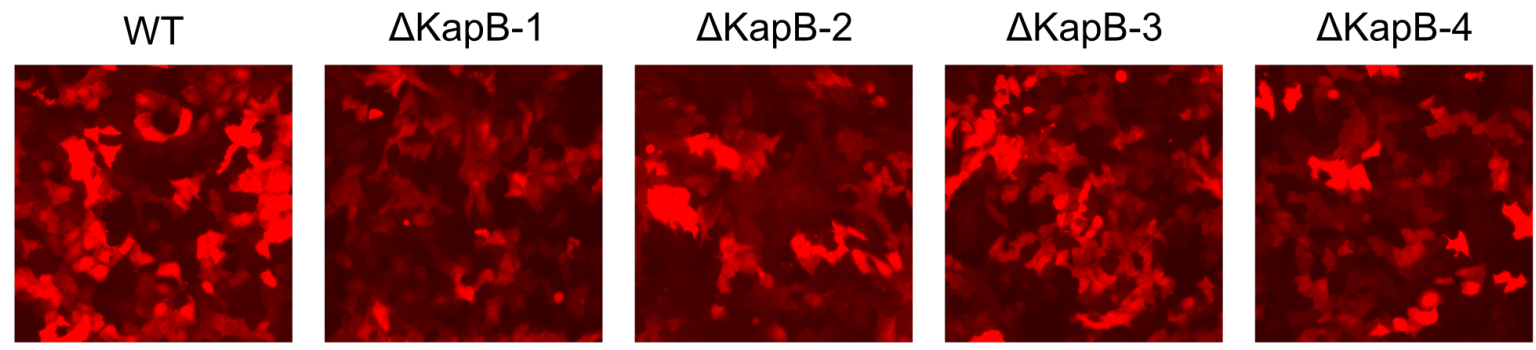

D
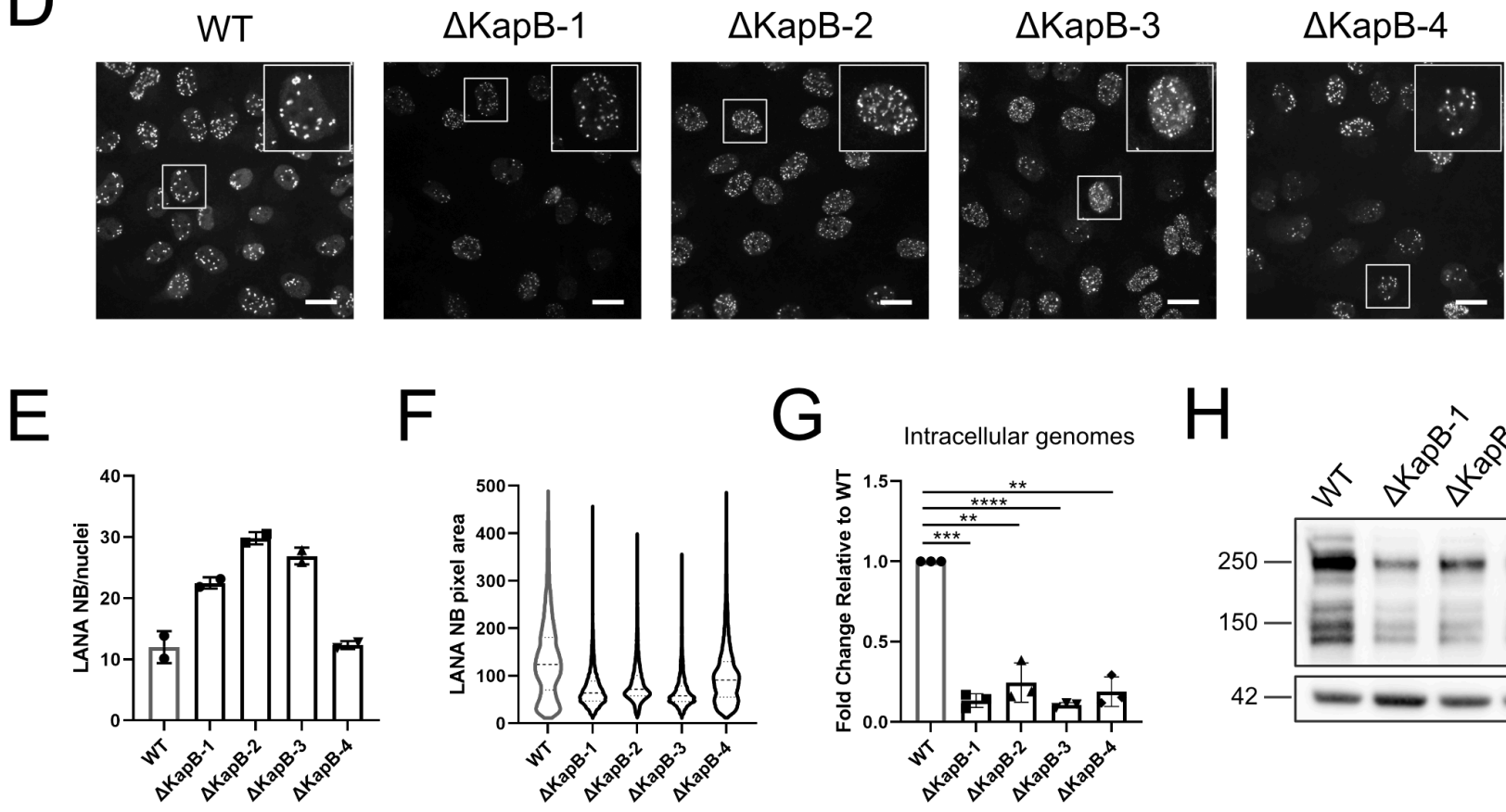

$\mathrm{H}$

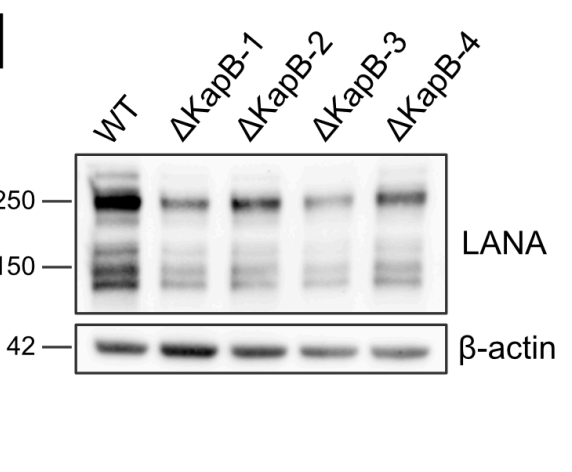


bioRxiv preprint doi: https://doi.org/10.1101/2021.06.11.448153; this version posted September 7, 2021. The copyright holder for this preprint (which was not certified by peer review) is the author/funder, who has granted bioRxiv a license to display the preprint in perpetuity. It is made available under aCC-BY-NC 4.0 International license.
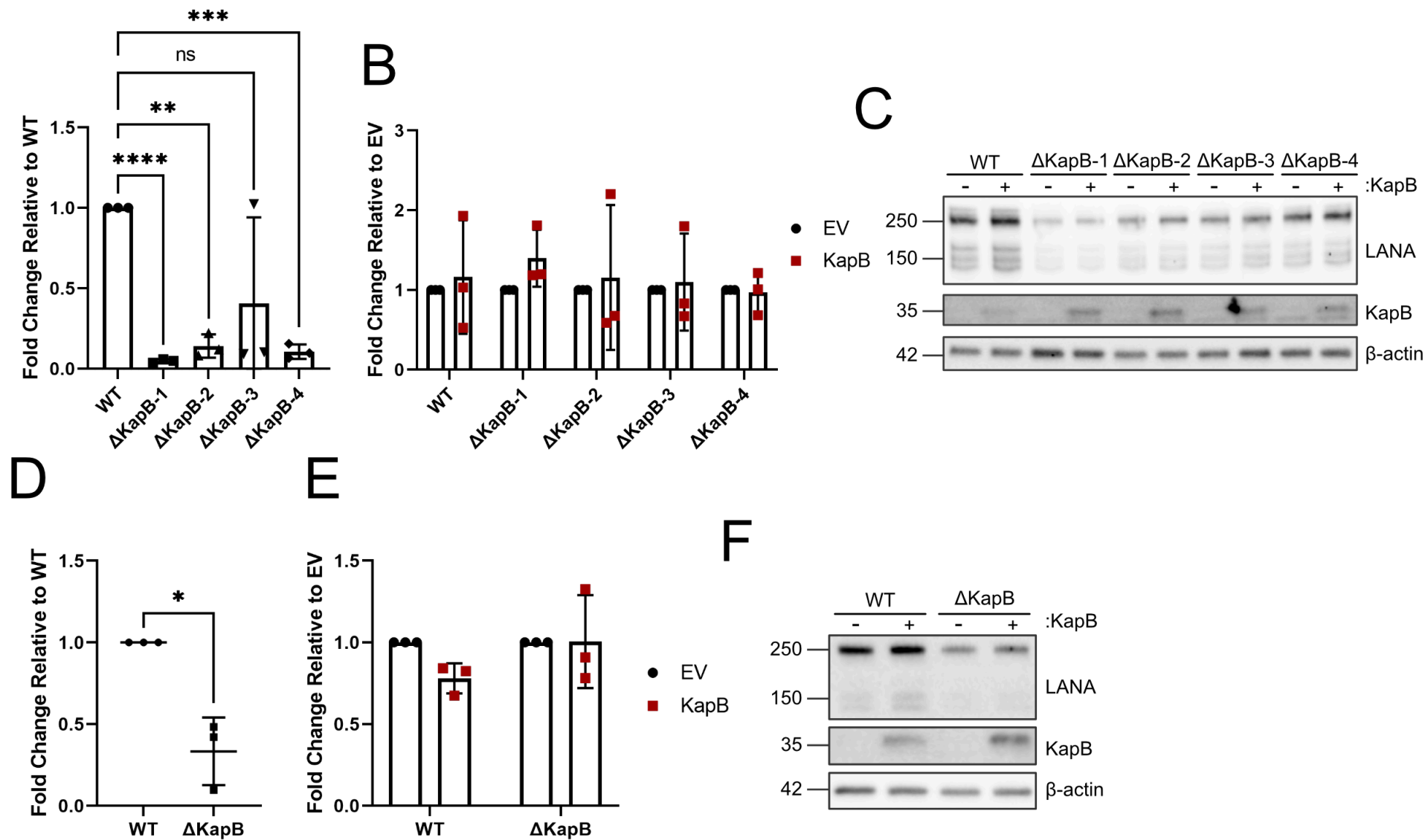

$\mathrm{F}$

G
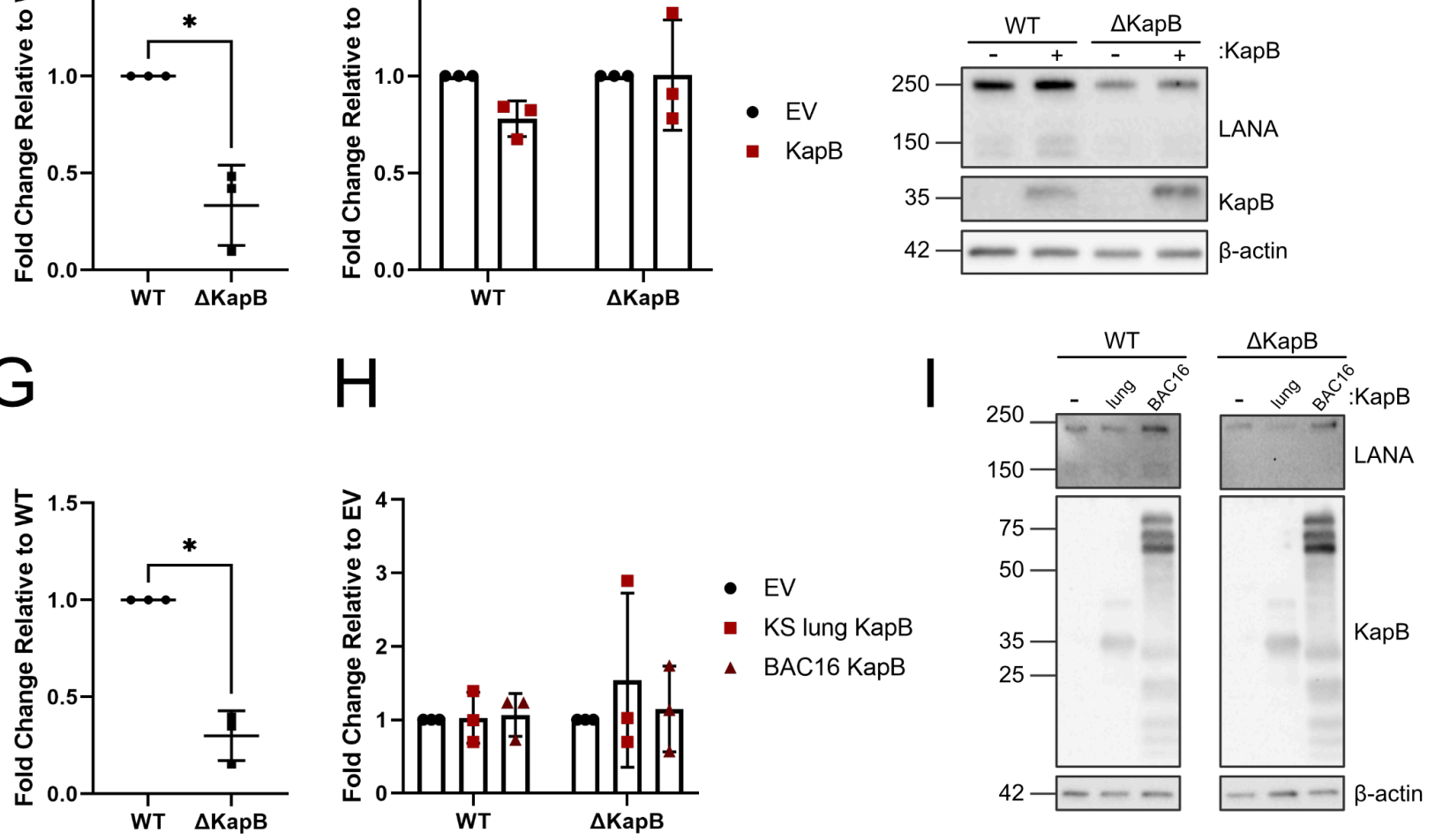
bioRxiv preprint doi: https://doi.org/10.1101/2021.06.11.448153; this version postedFfptember 7, 2021. The copyright holder for this preprint

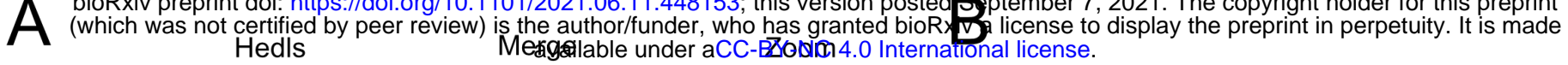
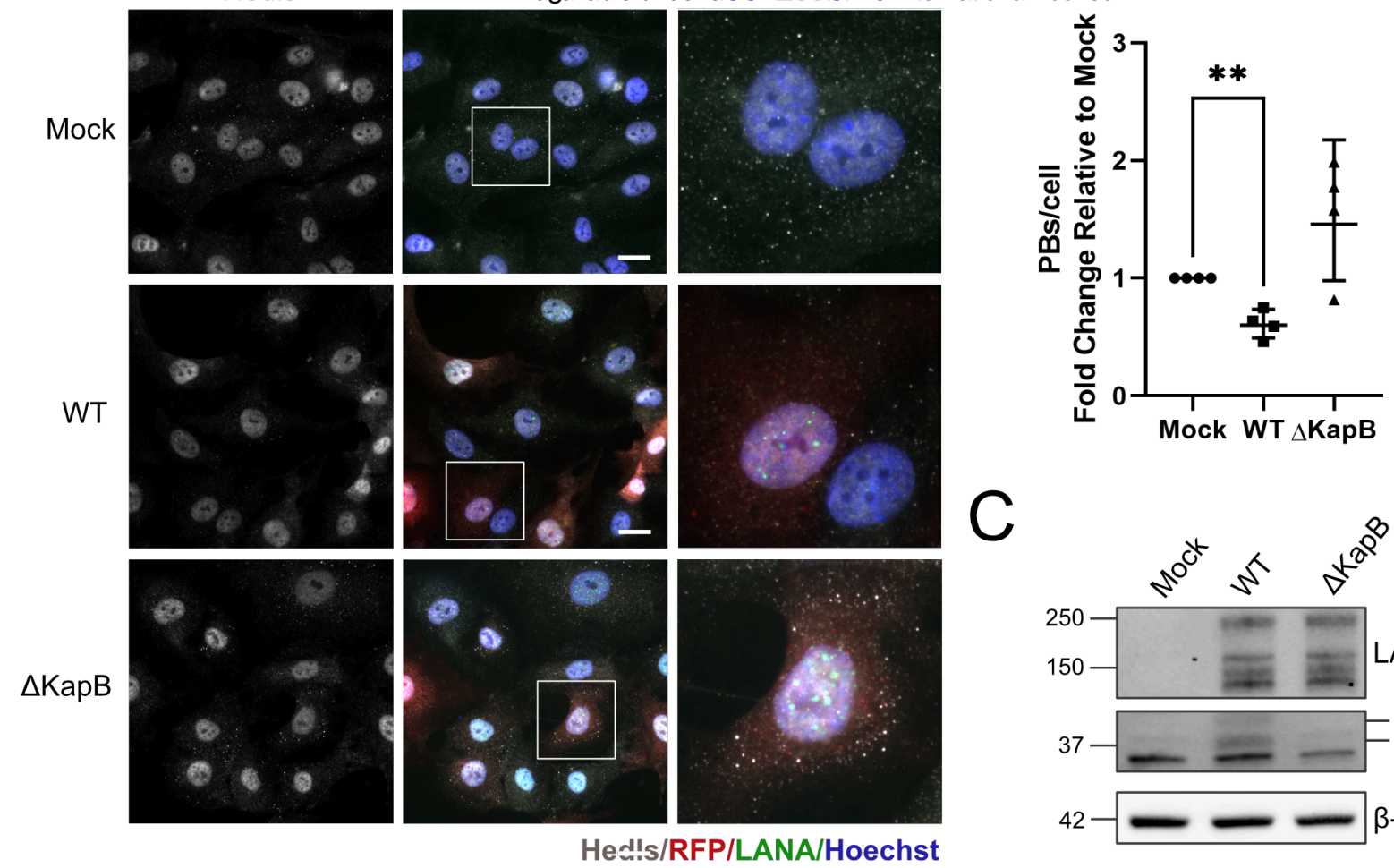

D
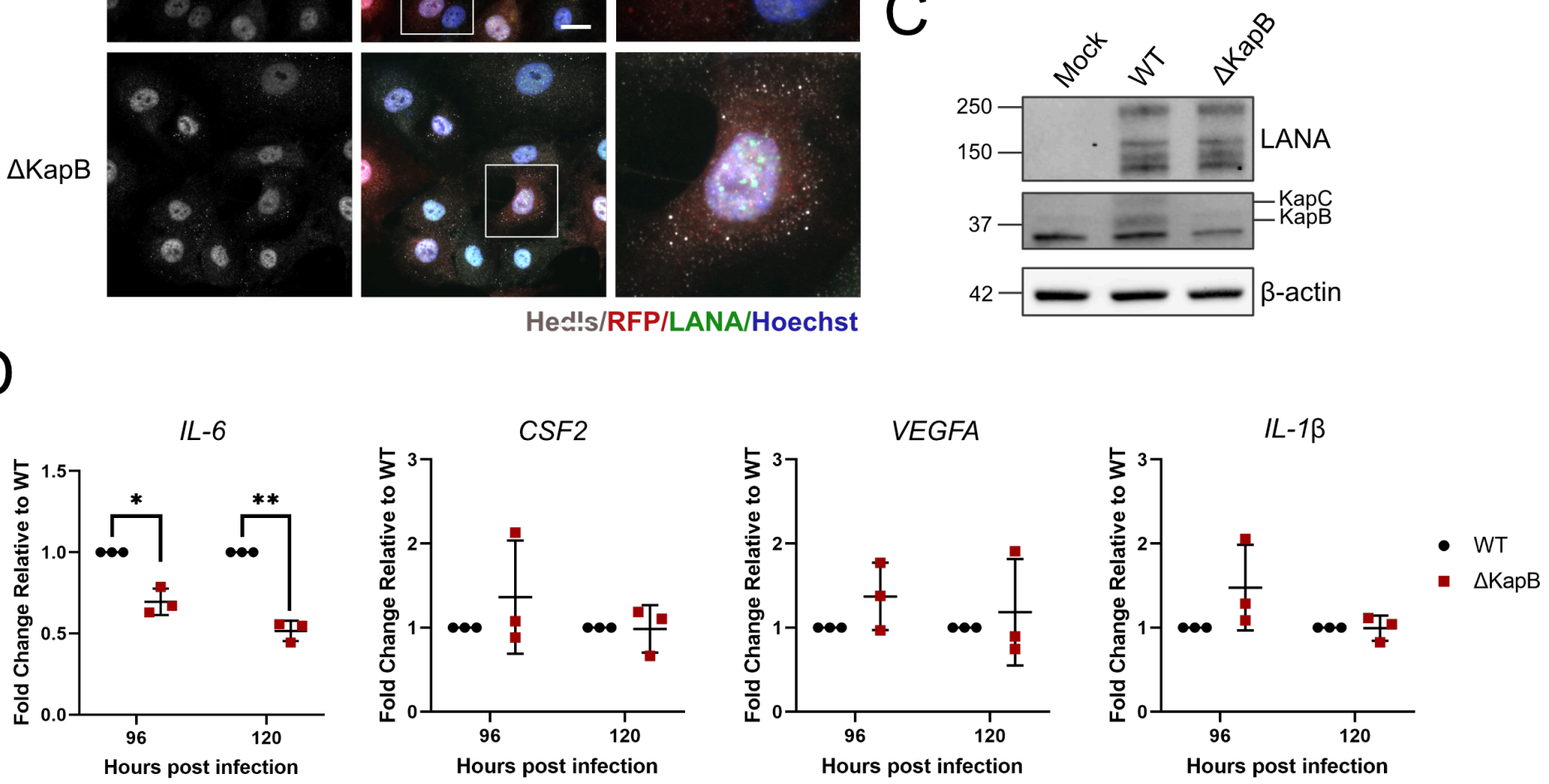
bioRxiv preprint doi: https://doi.org/10.1101/2021.06.11.448153; this version posted September 7, 2021. The copyright holder for this preprint (which was not certified by peer review) is the author/funder, who has granted bioRxiv a license to display the preprint in perpetuity. It is made

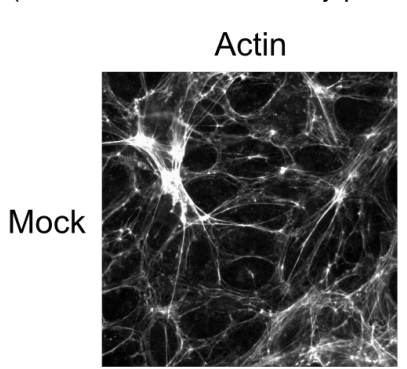
available under aCC-BY-NC 4.0 International license.
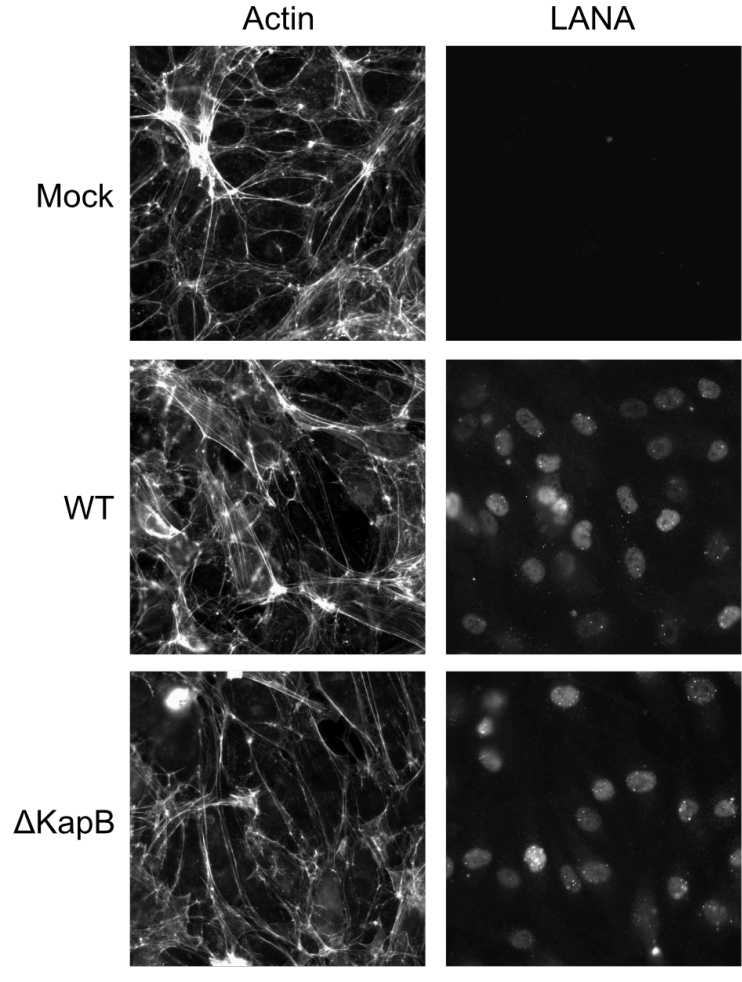
Merge
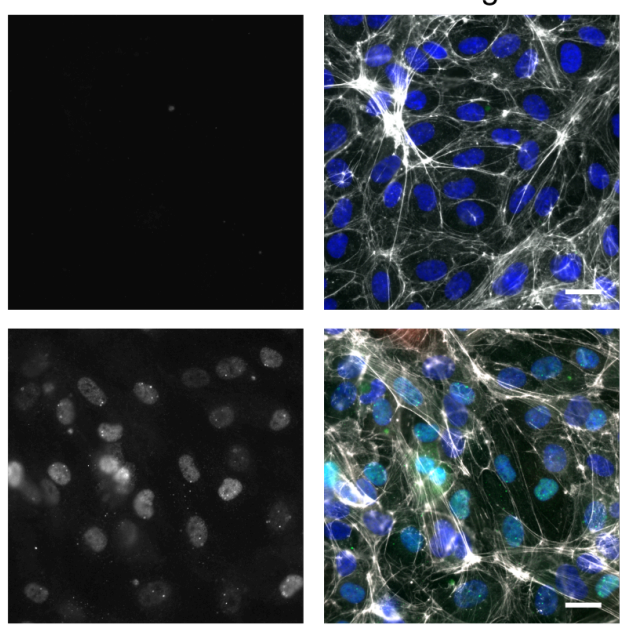

Brightfield
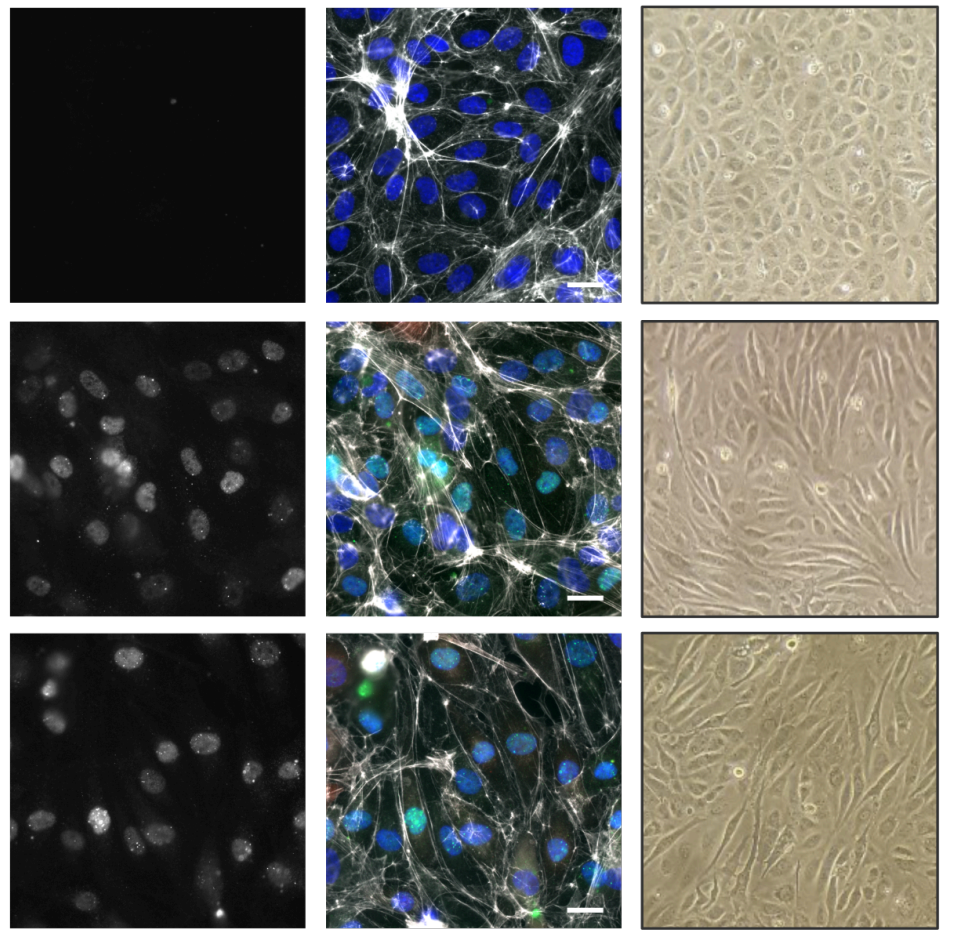

Actin/LANA/Hoechst 